This item was submitted to Loughborough's Research Repository by the author.

Items in Figshare are protected by copyright, with all rights reserved, unless otherwise indicated.

\title{
Microstructural and mechanical characterisation of Fe-14Cr-0.22Hf alloy fabricated by spark plasma sintering
}

PLEASE CITE THE PUBLISHED VERSION

https://doi.org/10.1016/j.jallcom.2018.05.196

\section{PUBLISHER}

(C) Elsevier

VERSION

AM (Accepted Manuscript)

\section{PUBLISHER STATEMENT}

This work is made available according to the conditions of the Creative Commons Attribution-NonCommercialNoDerivatives 4.0 International (CC BY-NC-ND 4.0) licence. Full details of this licence are available at: https://creativecommons.org/licenses/by-nc-nd/4.0/

\section{LICENCE}

CC BY-NC-ND 4.0

\section{REPOSITORY RECORD}

Auger, Maria A., Yina Huang, Hongtao Zhang, C.A. Jones, Zuliang Hong, M.P. Moody, Steve G. Roberts, and Patrick S. Grant. 2018. "Microstructural and Mechanical Characterisation of Fe-14cr-0.22hf Alloy Fabricated by Spark Plasma Sintering”. figshare. https://hdl.handle.net/2134/33315. 


\title{
Microstructural and mechanical characterisation of Fe-14Cr-0.22Hf alloy fabricated by spark plasma sintering
}

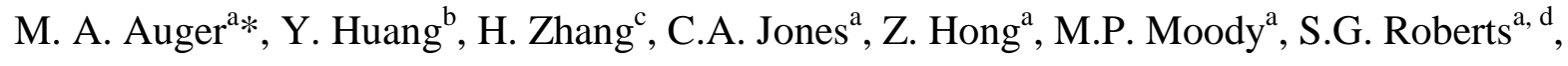 \\ P. S. Grant ${ }^{\mathrm{a}}$
}

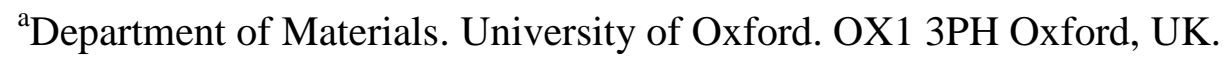

${ }^{\mathrm{b}}$ Hefei University of Technology. Hefei, Anhui, 230009, China

${ }^{\mathrm{c}}$ Department of Materials, Loughborough University, Leicestershire, LE11 3TU, UK

${ }^{\mathrm{d} C u l h a m ~ C e n t r e ~ f o r ~ F u s i o n ~ E n e r g y, ~ A b i n g d o n, ~ O x o n, ~ O X 14 ~ 3 E A, ~ U K . ~}$

*Corresponding Author. Address: Department of Materials. University of Oxford. Parks

Road. OX1 3PH Oxford, UK. Tel.: +44 (0) 1865 273694. Fax: +44 (0) 1865273789.

e-mail address: maria.auger@materials.ox.ac.uk (M. A. Auger)

\begin{abstract}
Fe-14Cr pre-alloyed powder and pure Hf powder were mechanically alloyed to produce powder with nominal composition $\mathrm{Fe}-14 \mathrm{Cr}-0.22 \mathrm{Hf}$ (wt. \%) that was consolidated by the spark plasma sintering (SPS) technique in order to investigate the ability of Hf to produce a nanometric dispersion of oxide particles in a ferritic matrix. Comprehensive microstructural and mechanical characterisation of the as-milled powder and the consolidated material was performed using electron microscopy, X-ray diffraction, atom probe tomography and indentation techniques. It was shown that Hf additions can effectively produce, by internal oxidation, a fine scale dispersion of Hf-O nanoparticles in the consolidated material. A uniform grain structure was produced in the alloy. Although the nanoparticle dispersion was not homogeneous at the finest scale, the resulting dispersion strengthening contributed
\end{abstract}


significantly to the hardness. According to these results, internal oxidation of reactive elements rather than direct addition of oxides may offer additional opportunities in the design and development of oxide dispersion strengthened steels.

Keywords: Powder metallurgy; hafnium; ODS steels; SPS; TEM; APT

\section{Introduction}

In the development of advanced materials for fission and fusion applications, oxide dispersion strengthened (ODS) steels are amongst the most promising structural materials [1-4]. Their microstructural stability under conditions of high temperature and high stress, resistance to radiation damage and creep resistance, have been extensively demonstrated [5-9]. This performance derives from a homogeneous dispersion of stable nanoparticles in the steel matrix that prevents dislocation motion and grain boundary sliding at high temperature [10]. These nanoparticles can also act as sinks for point defects and He bubbles under irradiation conditions in a nuclear reactor environment $[11,12]$, which underpins their excellent radiation resistance.

The manufacturing of ODS steels has been widely studied, with different combinations of processing routes investigated. The most common manufacturing approach usually starts with mechanical alloying of elemental or pre-alloyed powders with a low fraction of oxide particles (typically $\mathrm{Y}_{2} \mathrm{O}_{3}$ ) with the aim of providing a homogeneous dispersion of oxide nanoparticles in the final consolidated material [13-19]. The use of the spark plasma sintering (SPS) technique [20] to achieve the final densification of the milled powder, has increased in the last years, as it significantly shortens the time required for consolidation to a few minutes, compared with the several hours required for other sintering techniques such as hot isostatic 
pressing (HIP). In SPS, high current (1000 - 5000 A) and low voltage (<10 V) DC pulses and a uniaxial pressure (up to $100 \mathrm{MPa}$ ) are applied to a powder constrained in a graphite mould, which is heated at a high rate (up to $2000{ }^{\circ} \mathrm{C} / \mathrm{min}$ ) towards a target holding temperature. Isothermal holding times are typically $3-20 \mathrm{~min}$ and, as the current flow stops, the system rapidly cools down. A wide range of alloys, including $\mathrm{TaC}$ [21], transparent $\mathrm{Y}_{2} \mathrm{O}_{3}$ [22], Ni [23], $\mathrm{Al}_{2} \mathrm{O}_{3}$ [23], Ti-6Al-4V [24] or W-Ni-Fe [25], have been successfully consolidated by SPS. The effectiveness of this technique in the manufacture of ODS alloys has also been confirmed [26-29].

Hafnium has diverse potential uses in nuclear power reactors, such as thermal neutron absorber in nuclear energy control rods or as a specialized refractory material in elemental form or as hafnium oxide [30]. There are only limited reports of the production and characterization of Fe-Cr-Hf powder so far, but the effectiveness of Hf additions in promoting a dispersion of nanoparticles in mechanically alloyed and annealed powder has been suggested [31-33]. A recent study [34] has also reported effective irradiation resistance enhancement of a Fe-Cr-2Hf (wt.\%), cold compressed after mechanical alloying and powder annealing, under $200 \mathrm{keV}$ He irradiation at $500{ }^{\circ} \mathrm{C}$ by reducing void swelling, which is significant for potential nuclear uses of this alloy type. In this work, Hf powder was added to $\mathrm{Fe}-14 \mathrm{Cr}$ (wt. \%) pre-alloyed powder in order to evaluate its capacity to form a fine dispersion of nanoparticles in a ferritic alloy matrix and to consider the resulting performance with respect to more conventional ODS steels that typically contain $\mathrm{Y}_{2} \mathrm{O}_{3}[15,16,35]$. A 0.22 wt. $\%$ concentration of $\mathrm{Hf}$ in the alloy was selected to produce a final oxide fraction comparable with the $0.25 \mathrm{Y}_{2} \mathrm{O}_{3}$ (wt. \%) content in ODS alloys previously prepared and characterised by authors of the current work $[28,36]$. Addition of $\mathrm{Hf}$ to steel alloys already containing $\mathrm{Y}_{2} \mathrm{O}_{3}$ has been shown to promote the formation of finer oxides with respect to the original ODS 
alloy [37]. In this work, the effectiveness of $\mathrm{Hf}$ addition in promoting a nanometric dispersion of precipitates in a Fe-14Cr (wt. \%) alloy was compared with the widely studied use of direct $\mathrm{Y}_{2} \mathrm{O}_{3}$ additions.

\section{Materials and Methods}

Argon-atomised Fe-14Cr (wt. \%) pre-alloyed powder $(<150 \mu \mathrm{m}$ in diameter, Aubert \& Duval, France; composition details in Table I) and elemental Hf powder (-325 mesh, $99.6 \%$ pure, Alfa Aesar, UK, product number 10201) were used as starting materials to produce mechanically alloyed powder with nominal composition Fe-14Cr-0.22Hf (wt. \%) (referred to as $14 \mathrm{Hf}$ hereafter). The powder mixture was mechanically alloyed in a planetary ball mill (Fritsch Pulverisette 6) for $60 \mathrm{~h}$ at $150 \mathrm{rpm}$ in Ar atmosphere. AISI 52100 steel balls were used in the milling process at a ball-to powder ratio of 10:1. The grinding media were contained in a $500 \mathrm{ml}$ chrome-steel bowl. The milled powder was loaded into a graphite mould lined with graphite paper in an Ar-filled glove box for SPS consolidation.

The SPS process was performed at FCT Systeme GmbH (Rauenstein, Germany) using a uniaxial pressure of $50 \mathrm{MPa}$ for $5 \mathrm{~min}$. The hold temperature of $1150^{\circ} \mathrm{C}$ was reached at a heating rate of $100^{\circ} \mathrm{C} / \mathrm{min}$ to produce a consolidated disk of $\sim 20 \mathrm{~mm}$ diam. $\times 5 \mathrm{~mm}$ thick. Further details of the SPS process can be found in [28].

The milled powder was characterised by scanning electron microscopy (SEM), energy dispersive X-ray spectroscopy (EDS), X-ray diffraction (XRD), nanoindentation and atom probe tomography (APT) techniques. The powder sample was prepared for characterisation by embedding it in a conductive phenolic resin and polishing with $\mathrm{SiC}$ paper and colloidal silica suspension. The consolidated sample was characterised by SEM, EDS, synchrotron Xray diffraction, electron back-scattered diffraction (EBSD), Vickers hardness measurements, 
transmission electron microscopy (TEM) and APT. Different samples from the consolidated disk were cut, ground and polished with $\mathrm{SiC}$ paper and colloidal silica suspension $(0.06 \mu \mathrm{m}$ in size) for direct characterisation or for further TEM and APT sample preparation.

Microstructure and compositional imaging was performed in a JEOL JSM5510 scanning electron microscope equipped with an Oxford Instruments silicon drift detector (SDD). AZtec EDS analysis software was used for data processing. Standard $\theta-2 \theta$ X-ray diffraction measurements were obtained in a Philips PW1710 diffractometer, using $\mathrm{Cu}$ K $\alpha$ wavelength radiation $(\mathrm{E}=8.048 \mathrm{keV})$ at a voltage of $35 \mathrm{kV}$ and a current of $50 \mathrm{~mA}$. The scans were registered in the range $2 \theta=20^{\circ}-120^{\circ}$ in continuous mode using a step size of $0.02^{\circ}$ and a scan step time of $1.25 \mathrm{~s}$.

14Hf consolidated by SPS was mounted on an alumina holder and scanned by synchrotron Xray diffractometry on beamline I11 with a wavelength of $82.5770 \mathrm{pm}$ at the Diamond Light Source (Harwell Science and Innovation Campus, Didcot, UK). EBSD was conducted in a JEOL JSM6500F SEM operated at $20 \mathrm{kV}$ using a probe current of $\sim 10 \mathrm{nA}$; areas of $8 \times 12.5$ $\mu \mathrm{m}^{2}$ were mapped in a square array with a step size of $0.1 \mu \mathrm{m}$. TEM was conducted in a JEOL 2100 equipped with STEM-EDS operating at $200 \mathrm{kV}$ and in a JEOL 3000F operating at $300 \mathrm{kV}$. Samples suitable for TEM observation were prepared by the FIB lift-out technique combined with flash-polishing [36].

APT analysis was carried out in a CAMECA Instruments LEAP® 3000X-HR operating in laser pulsing mode. The specimen base temperature was around $50 \mathrm{~K}$ and the laser energy was $0.4 \mathrm{~nJ}$ at a repetition rate of $200 \mathrm{kHz}$. CAMECA IVAS® 3.6 .12 commercial software was used for data analysis and reconstruction. Samples suitable for APT characterisation, i. e. 
needle shaped with an end radius $<100 \mathrm{~nm}$, were prepared following two preparation routes: FIB lift-out and electropolishing. Samples from the milled powder embedded in phenolic conductive resin were prepared by the FIB lift-out technique [38]. The instrument used for APT and TEM sample preparation by the lift-out method was a Zeiss Auriga 40 FIB/SEM. Small bars with dimensions $0.5 \mathrm{~mm} \times 0.5 \mathrm{~mm} \times 20 \mathrm{~mm}$ were cut, ground and polished from the SPS consolidated disks. Each bar was submitted to a standard electropolishing process [39]: first, the specimen was repeatedly dipped into a layer of electrolyte ( $25 \%$ vol. perchloric acid $+75 \%$ vol. acetic acid) on top of a perfluorinated polyether (PFPE) inert liquid (Galden ${ }^{\mathrm{TM}}$ solution). A gold wire was used as counter electrode and a DC voltage of $15 \mathrm{~V}$, gradually reduced to $10-8 \mathrm{~V}$, was applied until the bar necked in the immersion region and split in two parts. Each part was refined to the final shape, i. e. having a final radius below $100 \mathrm{~nm}$ in the needle apex, by dipping the sample through a gold loop holding a drop of a milder electrolyte (2\% vol. perchloric acid $+98 \%$ vol. 2-butoxyethanol) and applying a DC voltage of $8-4 \mathrm{~V}$.

Nanoindentation measurements were made using a Nanoindenter XP (MTS, TN, USA) with a Berkovich diamond indenter calibrated against fused silica. The measurements were performed at room temperature in continuous stiffness mode, using a $2 \mathrm{~nm} 45 \mathrm{~Hz}$ harmonic displacement and reaching depths up to $2 \mu \mathrm{m}$ below the sample surface. Hardness measurements were performed at room temperature using a Vickers indenter and a load of 1 $\mathrm{kg}$ held for $10 \mathrm{~s} ; 15$ independent indentations were made.

\section{Results and discussion}

\section{SEM-EDS characterisation}


The morphology of the as-milled powder, observed by SEM in Fig. 1-a, shows that the powder particles were disc-shaped, with diameters of 200 to $300 \mu \mathrm{m}$ and thicknesses between 60 and $100 \mu \mathrm{m}$. An EDS spectrum from one of the powder particles displayed in Fig. 1-a is shown in Fig. 1-b with measured concentrations of $\mathrm{Fe}, \mathrm{Cr}$ and $\mathrm{Hf}$ in the as-milled powder that were in good agreement with the nominal alloy composition. There was some very limited $\mathrm{Si}$ contamination, most likely linked to the manufacturing process and/or impurities in the assupplied Fe-14Cr pre-alloyed powder. The surface of the SPS consolidated alloy is displayed in Fig. 2-a, showing some randomly distributed dark particles, sized $1-4 \mu \mathrm{m}$. The chemical maps shown in Fig. 2-b, performed on the central particle in Fig. 2-a, showed that these dark precipitates were rich in $\mathrm{Si}$, again suggesting $\mathrm{Si}$ impurities precipitated during consolidation. These precipitates were present in fractions too low to be detected by either laboratory or synchrotron XRD (see below).

\section{Laboratory XRD characterisation}

Laboratory $\theta-2 \theta$ X-ray diffractograms were obtained from the Hf powder used in the milling process and from the as-milled 14Hf powder. Fig. 3-a shows that the Hf powder was hexagonal, in accordance with the 638559 file in the FIZ Karlsruhe-ICSD database [40]. Two extra diffraction peaks were assigned to the phenolic resin in which the milled powder was embedded, confirmed by a resin-only diffraction measurement. Fig. 3-b shows the diffractogram from the as-milled $14 \mathrm{Hf}$ powder. No distinct, resolvable Hf peaks were present, implying that the Hf powder may have completely dissolved in the $\mathrm{Fe}-\mathrm{Cr}$ matrix after the mechanical alloying process, producing a single BCC ferrite solid solution.

\section{Synchrotron X-ray diffraction}


The synchrotron X-ray diffractogram obtained from 14Hf consolidated by SPS is shown in Fig. 4. Fig. 4-a shows the full synchrotron XRD pattern with both ferrite and austenite phases. Although $\mathrm{Fe}-14 \mathrm{Cr}$ (wt.\%) would not usually form austenite at any temperature, based on the Fe-Cr phase diagram [41], Hf may act as an austenite stabilizer according to the Fe-Hf phase diagram [41]. Austenite formed during the $1150^{\circ} \mathrm{C}$ high temperature SPS process was retained at room temperature due to the rapid cooling after consolidation. Fig. 4-b shows a zoomed-in count region from Fig. 4-a with orthorhombic and monoclinic $\mathrm{HfO}_{2}$ phases resolved, agreeing with 79913 [42] and 27313 [43] files respectively in the FIZ Karlsruhe-ICSD database. An overlap with $\mathrm{Cr}_{23} \mathrm{C}_{6}$ (JCPDS file number 035-0783) and $\mathrm{Cr}_{2} \mathrm{O}_{3}$ (JCPDS file number 38-1479) was also resolved. The $\mathrm{Al}_{2} \mathrm{O}_{3}$ peaks were associated with the sample holder used in the experiment.

\section{EBSD}

Fig. 5 shows an EBSD grain orientation map as an inverse pole figure (IPF) from the 14Hf alloy consolidated by SPS. High angle grain boundaries were defined as being those having a misorientation higher than $5^{\circ}$; sub-grain boundaries were defined as having a misorientation between $0^{\circ}$ and $5^{\circ}$. Most grains in the alloy were ferritic, with random grain orientation and a grain size in the range $0.5 \mu \mathrm{m}$ to $8 \mu \mathrm{m}$, with some occasional larger grains. The temperature used in the SPS process was $\sim 0.76 \mathrm{~T}_{\mathrm{m}}$ [41] of the Fe-14Cr alloy, where the growth of larger grains might be expected, so the presence of Hf may have conferred thermal stability to the microstructure. For comparison, two alloys with nominal composition Fe-14Cr-0.4Ti$0.25 \mathrm{Y}_{2} \mathrm{O}_{3}$ (wt.\%) and Fe-14Cr- $0.25 \mathrm{Y}_{2} \mathrm{O}_{3}-0.22 \mathrm{Hf}$ (wt.\%), mechanically alloyed and SPS consolidated under the same conditions, showed grain sizes up to $15 \mu \mathrm{m}$. [28, 36].

\section{TEM characterisation}


A general view of the microstructure of the 14Hf alloy consolidated by SPS at high magnification is shown in Fig. 6-a, with precipitates along grain boundaries. The grain microstructure was considerably uniform, with most grains in the range 1 to $5 \mu \mathrm{m}$ in size. As the atomic number of $\mathrm{Hf}(\mathrm{Z}=72)$ is much higher than those of $\mathrm{Fe}(\mathrm{Z}=26)$ and $\mathrm{Cr}(\mathrm{Z}=24)$, any second-phase precipitates should be relatively easy to resolve by high-angle annular darkfield (HAADF) imaging. Fig. 6-b shows dispersoids with brighter contrast than the matrix, arising from a higher average atomic number $(\mathrm{Z})$ and/or higher average density when compared with the Fe-Cr matrix. To confirm the chemical composition of the dispersoids, EDS mapping was performed and Fig. 7 shows a dispersoid enriched in $\mathrm{Hf}$ and $\mathrm{O}$ on a grain boundary. HR-TEM was used to investigate similar dispersoids in the matrix, but it was not possible to reliably index the resulting diffraction patterns, for which a contributory factor may be due to non-stoichiometric $\mathrm{HfO}_{x}$.

A total of 1119 particles were counted and measured from 26 micrographs taken at 5 different regions of the sample, including grain centres and regions containing grain boundaries, to produce the size distribution displayed in Fig. 8, with a typical dispersoid diameter of $2.0 \pm$ $1.5 \mathrm{~nm}$ and a number density of $0.8 \times 10^{23} \mathrm{~m}^{-3}$. Dispersoids of approximately $2 \mathrm{~nm}$ size were quite uniformly distributed. There was also a small fraction of larger dispersoids, up to $26 \mathrm{~nm}$ in size, mostly found on the grain boundaries where diffusion and coarsening can be expected to be relatively fast, although occasionally some were present in grain centres.

\section{APT characterisation}

APT was used to investigate the as-milled 14Hf powder and the consolidated alloy, with datasets consisting of $22-24$ million ions. The reconstructed ion maps for $14 \mathrm{Hf}$ powder are displayed in Fig. 9 and Video 1. A relatively uniform distribution of $\mathrm{Hf}$ in the Fe-Cr matrix 
was obtained after the alloy milling process. APT revealed a small $\mathrm{Cr}-\mathrm{O}$ precipitate that might have formed during milling or during subsequent powder handling. Fig. 10 shows reconstructed volumes from different regions in the 14Hf alloy after the SPS consolidation: a volume with no clusters in Fig. 10-a) and Video 2, a volume with $0.83 \times 10^{23} \mathrm{~m}^{-3}$ number density of clusters in Fig. 10-b) and Video 3, and a high number density of clusters $\left(2.37 \times 10^{23}\right.$ $\mathrm{m}^{-3}$ ) region in Fig. 10-c) and Video 4. The regions with no clusters, low density of clusters and high density of clusters represent 38, 27 and 35\%, respectively, of the analysed volume. The maximum separation method was implemented for cluster analysis [44], considering Hf$\mathrm{O}$ and $\mathrm{O}$ as ions being at the core of the clusters, with $\mathrm{Cr}-\mathrm{O}$ ions likely to be surrounding them, according to previous APT reconstruction of similar ODS steels containing Y-rich clusters [45]. The resulting cluster size (in terms of the Guinier diameter, i.e. twice the Guinier radius [46]) distribution from the APT measurements in the regions containing clusters is shown in Fig. 11-a and summarised in Table II. The average distance between each cluster and its first neighbour was also calculated as the distance between their centres of mass [46]; results for the high and low number density of clusters regions are summarised in Table II.

The shape of the clusters can be defined using a best-fit ellipsoid enclosing each individual cluster [47]. The smallest, middle and largest characteristic lengths of the best-fit ellipsoids were used to calculate the oblateness (smallest characteristic length / middle characteristic length) and the aspect ratio (middle characteristic length / largest characteristic length) of the clusters. Combinations of these two parameters can be used to define the cluster shape as sphere, rod, lath or disc. Fig. 11-b displays the oblateness and aspect ratio measurements for the clusters present in $14 \mathrm{Hf}$ consolidated by SPS, and the quantification of each cluster shape 
is summarised in Table III. The majority of the clusters, in both the regions containing clusters in high and low number density, were spherical.

The chemical composition of each cluster was also analysed by APT. Fig. 12 shows the O:Hf ratio for each individual cluster as a function of the cluster size, with a ratio close to $\mathrm{O}: \mathrm{Hf}=1$ for most of the clusters. An averaged ratio of $\mathrm{O}: \mathrm{Hf}=1.08 \pm 0.07$, for values in the range 1 to 1.27 was obtained for the clusters in the high density region, and $\mathrm{O}: \mathrm{Hf}=0.99 \pm 0.02$ in a 0.93 to 1.01 range for clusters in the low density region. This demonstrates that there was $\mathrm{Hf}$ and $\mathrm{O}$ enrichment of the clusters, but not reaching the $\mathrm{HfO}_{2}$ stoichiometry. Possible Hf-containing precipitates include $\mathrm{HfO}_{2}$, $\mathrm{HfC}$ and $\mathrm{Hf}$-containing intermetallic compounds. The Gibbs free energy for the formation of $\mathrm{HfO}_{2}$ and $\mathrm{HfC}$ at $1150^{\circ} \mathrm{C}$ are $\Delta \mathrm{G}_{\mathrm{f}}\left(\mathrm{HfO}_{2}\right)=-1306 \mathrm{~kJ} / \mathrm{mol}$ according to [48] and $\Delta \mathrm{G}_{\mathrm{f}}(\mathrm{HfC})=-219 \mathrm{~kJ} / \mathrm{mol}$ according to [49]. The Gibbs free energy for the formation of intermetallics would be $\sim-100 \mathrm{~kJ} / \mathrm{mol}$ according to [32]. In the present work, due to the 0.22 wt. \% Hf concentration, only sub-stoichiometric Hf-O particles have formed. The sub-stoichiometric Hf-O dispersoids were likely responsible for the orthorhombic and monoclinic phases observed in the synchrotron X-ray diffractograms (Fig. 4-b). Also, the dispersoid size being typically $<5 \mathrm{~nm}$, suggests that precipitation occurred during the relatively short $(5 \mathrm{~min})$ thermal exposure of the SPS process, but there is little evidence for any significant dispersoid coarsening after initial nucleation.

\section{Hardness measurements}

The nanoindentation hardness profile of the as-milled 14Hf powder is shown in Fig. 13-a. Apart from a slight variation associated with the initial penetration of the polished surface of powders, the hardness tends to an approximately constant value of $7.74 \pm 0.27 \mathrm{GPa}$ with increasing indentation depth. This comparatively high hardness could be associated with 
strain hardening induced during the mechanical alloying process and/or the indentation size effect by which hardness values at sub- $\mu$ m indentation depths can be 2-3 times those of macroscopic indentations [50]. Vickers hardness measurements were performed on the consolidated 14Hf (Fig. 13-b), with 15 random indentations over the sample surface giving an average $2.31 \pm 0.13 \mathrm{GPa}, \sim 30 \%$ lower than that for a $\mathrm{Fe}-14 \mathrm{Cr}-0.3 \mathrm{Y}_{2} \mathrm{O}_{3}$ (wt. \%) alloy consolidated by HIP (hardness $=3.60 \pm 0.08 \mathrm{GPa}$ ) [27]. The hardness of a Fe-14Cr (wt. \%) alloy manufactured by SPS at $1150^{\circ} \mathrm{C}$ was $1.74 \pm 0.04 \mathrm{GPa}$ [27]; this will be taken as a "base value" when assessing effects of possible hardening mechanisms. The difference in hardness between the ODS alloys containing Hf and Y might be due to differences in the contributions to the flow stress of solid solution strengthening, dislocation strengthening, dispersion strengthening and/or fine grain strengthening $[31,51]$. It is likely that the contributions from solid solution strengthening contribution are similar in the two alloys, as the matrix is Fe$14 \mathrm{Cr}$ (wt. \%) in both cases and both $\mathrm{Y}$ and $\mathrm{Hf}$ are virtually insoluble in the matrix at equilibrium. It may be assumed that dislocation strengthening had a relatively weak effect because no dislocations were observed by TEM (Fig. 6 and $[16,45]$ ). Regarding grain size strengthening ('Hall-Petch' effect [52]), the 14Hf alloy has a relatively uniform grain size of 1 to $5 \mu \mathrm{m}$; Fe- $14 \mathrm{Cr}-0.3 \mathrm{Y}_{2} \mathrm{O}_{3}$ consolidated by HIP also had a uniform grain structure with slightly smaller grains, in the range 0.5 to $3 \mu \mathrm{m}[16])$, significantly contributing to the hardness as shown in Table IV.

The dispersion strengthening contribution, $H_{O}$, can be estimated by assuming Orowan strengthening, according to $[31,53]$ :

$$
H_{O}=3 \sqrt{3}\left(\frac{\ln \left(d / r_{0}\right)}{\ln \left(L / r_{0}\right)}\right)^{3 / 2} \frac{G b}{L} \frac{\ln \left(L / r_{0}\right)}{2 \pi}
$$

where $d$ is the precipitate size (taken as the cluster diameter from APT measurements in Table II), $L$ is the interprecipitate spacing (taken as the intercluster distance from APT measurements in Table II), $G$ is the shear modulus for Fe ( $82 \mathrm{GPa}), b$ is the Burgers vector 
$(0.384 \mathrm{~nm})$ and $r_{0}$ is the dislocation core radius, assumed to be four times the Burgers vector $(1.536 \mathrm{~nm})$. As the dispersion of nanoparticles is not homogeneous, the contributions to Orowan hardening from the regions of high and low number density of clusters has been considered separately taking into account the respective cluster analysis and volumes represented by each region type obtained by APT characterisation. The calculations are detailed in Table $\mathrm{V}$ and summarised in Table IV. The most significant contribution to the total hardness in both alloys is Orowan hardening. The Orowan hardening is significantly higher for the Fe-14Cr- $0.3 \mathrm{Y}_{2} \mathrm{O}_{3}$ (wt. \%) alloy consolidated by HIP than for $14 \mathrm{Hf}$ consolidated by SPS because the cluster number density is higher $\left(3.30 \times 10^{23} \mathrm{~m}^{-3}[45]\right)$, the cluster size is smaller $(3.06 \pm 0.68 \mathrm{~nm}[45])$ and the clusters are closer together (intercluster distance $=9.87$ $\pm 2.37 \mathrm{~nm})$.

\section{Conclusions}

- The effectiveness of elemental Hf addition to a ferritic steel powder to promote a nanometric distribution of clusters in the densified steel has been demonstrated. Elemental Hf dissolved in the Fe-14Cr (wt. \%) matrix during the mechanical alloying and then precipitated as Hf-O rich clusters during SPS consolidation. The approach is an alternative to the more common adding of ceramic oxides, such as $\mathrm{Y}_{2} \mathrm{O}_{3}$, directly to ferritic powders.

- Hf-O dispersoids stabilised a relatively uniform grain structure, with grain sizes between 1 and $5 \mu \mathrm{m}$, although Hf-O nanoparticle dispersion was not homogeneous at the finest scale, as both regions with no particles and regions with high and low number density of Hf-O rich precipitates were observed by APT. The cluster size of the precipitates was approximately $2 \mathrm{~nm}$ by TEM, with a number density of $0.8 \times 10^{23} \mathrm{~m}^{-3}$. The cluster size measured by APT was $2.34 \pm 0.77 \mathrm{~nm}$ in the region with a high number density of 
clusters $\left(2.37 \times 10^{23} \mathrm{~m}^{-3}\right)$ and $3.64 \pm 0.98 \mathrm{~nm}$ in the region with a low number density of clusters $\left(0.83 \times 10^{23} \mathrm{~m}^{-3}\right)$.

- After SPS consolidation, Hf was predominantly in the form of Hf-O precipitates, with orthorhombic and monoclinic crystalline structures, with a O:Hf ratio close to 1 . No other Hf-rich compounds such as HfC or Fe-Cr-Hf were detected.

- Dispersion strengthening was the primary contribution to the final hardness, consistent with conventional ODS steels using direct oxide additions.

\section{Acknowledgements}

The authors acknowledge funding by the UK Engineering and Physical Sciences Research Council (EPSRC) through Grant Numbers EP/H018921/1 and EP/P006566 (MAPP), Diamond Light Source for access to beamline I11 (Proposal No. EE10597) and the use of the EPSRC funded National Chemical Database Service hosted by the Royal Society of

Chemistry.

\section{References}

[1] G.R. Odette, M.J. Alinger, B.D. Wirth, Recent developments in irradiation-resistant steels, Annu Rev Mater Res 38 (2008) 471-503.

[2] A. Hirata, T. Fujita, Y.R. Wen, J.H. Schneibel, C.T. Liu, M.W. Chen, Atomic structure of nanoclusters in oxide-dispersion-strengthened steels, Nat Mater 10(12) (2011) 922-926.

[3] G.R. Odette, Recent Progress in Developing and Qualifying Nanostructured Ferritic Alloys for Advanced Fission and Fusion Applications, Jom-Us 66(12) (2014) 2427-2441.

[4] R.L. Klueh, J.P. Shingledecker, R.W. Swindeman, D.T. Hoelzer, Oxide dispersion-strengthened steels: A comparison of some commercial and experimental alloys, J Nucl Mater 341(2-3) (2005) 103-114.

[5] P. Pareige, M.K. Miller, R.E. Stoller, D.T. Hoelzer, E. Cadel, B. Radiguet, Stability of nanometer-sized oxide clusters in mechanically-alloyed steel under ion-induced displacement cascade damage conditions, J Nucl Mater 360(2) (2007) 136-142.

[6] T.R. Allen, J. Gan, J.I. Cole, M.K. Miller, J.T. Busby, S. Shutthanandan, S. Thevuthasan, Radiation response of a 9 chromium oxide dispersion strengthened steel to heavy ion irradiation, J Nucl Mater 375(1) (2008) 26-37. [7] A. Certain, S. Kuchibhatla, V. Shutthanandan, D.T. Hoelzer, T.R. Allen, Radiation stability of nanoclusters in nano-structured oxide dispersion strengthened (ODS) steels, J Nucl Mater 434(1-3) (2013) 311-321.

[8] V. de Castro, S. Lozano-Perez, M. Briceno, P. Trocellier, S.G. Roberts, R. Pareja, Effects of single- and simultaneous triple-ion-beam irradiation on an oxide dispersion-strengthened Fe12Cr steel, J Mater Sci 50(5) (2015) 2306-2317.

[9] T.Y. Chen, E. Aydogan, J.G. Gigax, D. Chen, J. Wang, X.M. Wang, S. Ukai, F.A. Garner, L. Shao, Microstructural changes and void swelling of a 12Cr ODS ferritic-martensitic alloy after high-dpa self-ion irradiation, J Nucl Mater 467 (2015) 42-49.

[10] F. Siska, L. Stratil, H. Hadraba, S. Fintova, I. Kubena, T. Zalezak, D. Bartkova, High temperature deformation mechanisms in the 14\% Cr ODS alloy, Materials Science and Engineering: A 689 (2017) 34-39. 
[11] M. Šćepanović, V. de Castro, T. Leguey, M.A. Auger, S. Lozano-Perez, R. Pareja, Microstructural stability of ODS Fe-14Cr (-2W-0.3Ti) steels after simultaneous triple irradiation, Nuclear Materials and Energy 9 (2016) 490-495.

[12] C.M. Parish, K.A. Unocic, L. Tan, S.J. Zinkle, S. Kondo, L.L. Snead, D.T. Hoelzer, Y. Katoh, Helium sequestration at nanoparticle-matrix interfaces in helium + heavy ion irradiated nanostructured ferritic alloys, $\mathrm{J}$ Nucl Mater 483 (2017) 21-34.

[13] M.J. Alinger, G.R. Odette, D.T. Hoelzer, On the role of alloy composition and processing parameters in nanocluster formation and dispersion strengthening in nanostuctured ferritic alloys, Acta Mater 57(2) (2009) 392-406.

[14] M.A. Auger, T. Leguey, A. Munoz, M.A. Monge, V. de Castro, P. Fernandez, G. Garces, R. Pareja, Microstructure and mechanical properties of ultrafine-grained $\mathrm{Fe}-14 \mathrm{Cr}$ and ODS Fe-14Cr model alloys, J Nucl Mater 417(1-3) (2011) 213-216.

[15] P. He, M. Klimenkov, R. Lindau, A. Moslang, Characterization of precipitates in nano structured $14 \% \mathrm{Cr}$ ODS alloys for fusion application, J Nucl Mater 428(1-3) (2012) 131-138.

[16] M.A. Auger, V. de Castro, T. Leguey, M.A. Monge, A. Munoz, R. Pareja, Microstructure and tensile properties of oxide dispersion strengthened Fe-14Cr-0.3Y(2)O(3) and Fe-14Cr-2W-0.3Ti-0.3Y(2)O(3), J Nucl Mater 442(1-3) (2013) S142-S147.

[17] Z. Oksiuta, P. Hosemann, S.C. Vogel, N. Baluc, Microstructure examination of Fe-14Cr ODS ferritic steels produced through different processing routes, J Nucl Mater 451(1-3) (2014) 320-327.

[18] D.T. Hoelzer, K.A. Unocic, M.A. Sokolov, T.S. Byun, Influence of processing on the microstructure and mechanical properties of 14YWT, J Nucl Mater 471 (2016) 251-265.

[19] C.C. Eiselt, H. Schendzielorz, A. Seubert, B. Hary, Y. de Carlan, P. Diano, B. Perrin, D. Cedat, ODSmaterials for high temperature applications in advanced nuclear systems, Nuclear Materials and Energy 9 (2016) 22-28.

[20] Z.A. Munir, D.V. Quach, M. Ohyanagi, Electric Current Activation of Sintering: A Review of the Pulsed Electric Current Sintering Process, J Am Ceram Soc 94(1) (2011) 1-19.

[21] L.M. Liu, F. Ye, Y. Zhou, New route to densify tantalum carbide at 1400 degrees C by spark plasma sintering, Mat Sci Eng A 528(13-14) (2011) 4710-4714.

[22] L.Q. An, A. Ito, T. Goto, Transparent yttria produced by spark plasma sintering at moderate temperature and pressure profiles, J Eur Ceram Soc 32(5) (2012) 1035-1040.

[23] L. Minier, S. Le Gallet, Y. Grin, F. Bernard, A comparative study of nickel and alumina sintering using spark plasma sintering (SPS), Mater. Chem. Phys. 134(1) (2012) 243-253.

[24] K. Crosby, L.L. Shaw, C. Estournes, G. Chevallier, A.W. Fliflet, M.A. Imam, Enhancement in Ti-6Al-4V sintering via nanostructured powder and spark plasma sintering, Powder Metall. 57(2) (2014) 147-154.

[25] V.N. Chuvildeev, D.V. Panov, M.S. Boldin, A.V. Nokhrin, Y.V. Blagoveshchensky, N.V. Sakharov, S.V. Shotin, D.N. Kotkov, Structure and properties of advanced materials obtained by Spark Plasma Sintering, Acta Astronaut. 109 (2015) 172-176.

[26] C. Heintze, M. Hernandez-Mayoral, A. Ulbricht, F. Bergner, A. Shariq, T. Weissgarber, H. Frielinghaus, Nanoscale characterization of ODS Fe-9\% Cr model alloys compacted by spark plasma sintering, J Nucl Mater 428(1-3) (2012) 139-146.

[27] M.A. Auger, V. de Castro, T. Leguey, A. Munoz, R. Pareja, Microstructure and mechanical behavior of ODS and non-ODS Fe-14Cr model alloys produced by spark plasma sintering, J Nucl Mater 436(1-3) (2013) 6875.

[28] H.T. Zhang, Y.N. Huang, H.P. Ning, C.A. Williams, A.J. London, K. Dawson, Z.L. Hong, M.J. Gorley, C.R.M. Grovenor, G.J. Tatlock, S.G. Roberts, M.J. Reece, H.X. Yan, P.S. Grant, Processing and microstructure characterisation of oxide dispersion strengthened Fe-14Cr-0.4Ti-0.25Y(2) $\mathrm{O}(3)$ ferritic steels fabricated by spark plasma sintering, J Nucl Mater 464 (2015) 61-68.

[29] I. Hilger, X. Boulnat, J. Hoffmann, C. Testani, F. Bergner, Y. De Carlan, F. Ferraro, A. Ulbricht, Fabrication and characterization of oxide dispersion strengthened (ODS) 14Cr steels consolidated by means of hot isostatic pressing, hot extrusion and spark plasma sintering, J Nucl Mater 472 (2016) 206-214.

[30] E.M. Harper, Z. Diao, S. Panousi, P. Nuss, M.J. Eckelman, T.E. Graedel, The criticality of four nuclear energy metals, Resources, Conservation and Recycling 95 (2015) 193-201.

[31] L.L. Li, M. Saber, W.Z. Xu, Y.T. Zhu, C.C. Koch, R.O. Scattergood, High-temperature grain size stabilization of nanocrystalline Fe-Cr alloys with Hf additions, Mat Sci Eng A 613 (2014) 289-295.

[32] W.Z. Xu, L.L. Li, M. Saber, C.C. Koch, Y.T. Zhu, R.O. Scattergood, Microstructures and Stabilization Mechanisms of Nanocrystalline Iron-Chromium Alloys with Hafnium Addition, Metall Mater Trans A 46a(9) (2015) 4394-4404.

[33] P.S. Roodposhti, M. Saber, C. Koch, R. Scattergood, S. Shahbazmohamadi, Effect of oxygen content on thermal stability of grain size for nanocrystalline Fe10Cr and Fe14Cr4Hf alloy powders, J Alloy Compd 720 (2017) 510-520. 
[34] W.Z. Xu, L.L. Li, J.A. Valdez, M. Saber, Y.T. Zhu, C.C. Koch, R.O. Scattergood, Effect of nano-oxide particle size on radiation resistance of iron-chromium alloys, J Nucl Mater 469 (2016) 72-81.

[35] M.K. Miller, K.F. Russell, D.T. Hoelzer, Characterization of precipitates in MA/ODS ferritic alloys, J Nucl Mater 351(1-3) (2006) 261-268.

[36] Y. Huang, H. Zhang, M.A. Auger, Z. Hong, H. Ning, M.J. Gorley, P.S. Grant, M.J. Reece, H. Yan, S.G. Roberts, Microstructural comparison of effects of hafnium and titanium additions in spark-plasma-sintered Febased oxide-dispersion strengthened alloys, J Nucl Mater 487 (2017) 433-442.

[37] H. Oka, M. Watanabe, S. Ohnuki, N. Hashimoto, S. Yamashita, S. Ohtsuka, Effects of milling process and alloying additions on oxide particle dispersion in austenitic stainless steel, J Nucl Mater 447(1-3) (2014) 248253.

[38] M.K. Miller, K.F. Russell, Atom probe specimen preparation with a dual beam SEM/FIB miller, Ultramicroscopy 107(9) (2007) 761-766.

[39] B. Gault, Atom probe microscopy, Springer, New York, 2012.

[40] R.B. Russell, On the Zr-Hf System, J Appl Phys 24(2) (1953) 232-233.

[41] W.G. Moffatt, General Electric Company., The handbook of binary phase diagrams, General Electric Co, Schenectady, 1978.

[42] O. Ohtaka, T. Yamanaka, S. Kume, N. Hara, H. Asano, F. Izumi, Structural-analysis of orthorhombic hafnia by neutron powder diffraction, J Am Ceram Soc 78(1) (1995) 233-237.

[43] R. Ruh, P.W. Corfield, Crystal Structure of Monoclinic Hafnia and Comparison with Monoclinic Zirconia, J Am Ceram Soc 53(3) (1970) 126-+.

[44] M.K. Miller, Atom probe tomography : analysis at the atomic level, Kluwer Academic/Plenum Publishers, New York ; London, 2000.

[45] M.A. Auger, V. de Castro, T. Leguey, S. Lozano-Perez, P.A.J. Bagot, M.P. Moody, S.G. Roberts, Effect of the milling atmosphere on the microstructure and mechanical properties of a ODS Fe-14Cr model alloy, Mat Sci Eng A 671 (2016) 264-274.

[46] M.K. Miller, E.A. Kenik, Atom probe tomography: A technique for nanoscale characterization, Microsc Microanal 10(3) (2004) 336-341.

[47] R.K.W. Marceau, L.T. Stephenson, C.R. Hutchinson, S.P. Ringer, Quantitative atom probe analysis of nanostructure containing clusters and precipitates with multiple length scales, Ultramicroscopy 111(6) (2011) 738-742.

[48] M.C. Zeman, C.C. Fulton, G. Lucovsky, R.J. Nemanich, W.C. Yang, Thermal stability of TiO2, ZrO2, or HfO2 on Si(100) by photoelectron emission microscopy, J Appl Phys 99(2) (2006).

[49] Y.C. Ye, H. Zhang, Y.G. Tong, S.X. Bai, HfC-based coating prepared by reactive melt infiltration on C/C composite substrate, Ceram Int 39(5) (2013) 5477-5483.

[50] W.D. Nix, H.J. Gao, Indentation size effects in crystalline materials: A law for strain gradient plasticity, J Mech Phys Solids 46(3) (1998) 411-425.

[51] X.D. Mao, S.H. Kang, T.K. Kim, S.C. Kim, K.H. Oh, J. Jang, Microstructure and Mechanical Properties of Ultrafine-Grained Austenitic Oxide Dispersion Strengthened Steel, Metall Mater Trans A 47a(11) (2016) 53345343.

[52] X.D. Liu, M. Nagumo, M. Umemoto, The Hall-Petch Relationship in Nanocrystalline Materials, Materials Transactions, JIM 38(12) (1997) 1033-1039.

[53] D.J. Bacon, U.F. Kocks, R.O. Scattergood, The effect of dislocation self-interaction on the orowan stress, Philosophical Magazine 28(6) (1973) 1241-1263. 


\section{Table captions}

Table I. Chemical composition of the Fe-14Cr (wt. \%) pre-alloyed powder.

Table II. Summary of the cluster size, intercluster distance and number density of clusters in the $14 \mathrm{Hf}$ alloy consolidated by SPS in the low and high cluster density regions.

Table III. Summary of the cluster shape in the regions with low and high number density of clusters in the14Hf alloy consolidated by SPS.

Table IV. Summary of hardness, total hardening, Orowan and Hall-Petch contributions to the total hardening for the $14 \mathrm{Hf}$ alloy consolidated by SPS and $\mathrm{Fe}-14 \mathrm{Cr}-0.3 \mathrm{Y}_{2} \mathrm{O}_{3}$ (wt.\%) alloy consolidated by HIP [27, 45]. Hardness of Fe-14Cr consolidated by SPS is shown as the reference value [27].

Table V. Orowan hardness calculations for the $14 \mathrm{Hf}$ alloy consolidated by SPS considering the different cluster density regions observed by APT. 


\section{Figure captions}

Fig. 1. a) SEM image of as-milled $14 \mathrm{Hf}$ powder. b) EDS quantification of one $14 \mathrm{Hf}$ powder particle.

Fig. 2 a) SEM image of 14Hf alloy consolidated by SPS. b) SEM image, mapping and EDS analysis of $\mathrm{Fe}, \mathrm{Cr}$ and $\mathrm{Si}$ of one dark particle in the 14Hf alloy consolidated by SPS.

Fig. 3. X-ray diffraction patterns of a) elemental Hf powder and b) as-milled 14Hf powder highlighting the phases present.

Fig. 4. Synchrotron X-ray diffraction patterns of $14 \mathrm{Hf}$ alloy consolidated by SPS. a) Overview of the pattern. b) zoomed-in pattern to show minor phases.

Fig. 5. EBSD inverse pole figure (IPF) map of 14Hf alloy consolidated by SPS. Grain orientations are colour-coded according to the inset standard triangle.

Fig. 6. a) Bright field TEM and b) HAADF images of 14Hf alloy consolidated by SPS.

Fig. 7. STEM DF image and EDS mapping of Fe, $\mathrm{Cr}$, Hf and $\mathrm{O}$ in $14 \mathrm{Hf}$ alloy consolidated by SPS.

Fig. 8. Size distribution of the nanoparticles from TEM analysis in the $14 \mathrm{Hf}$ alloy consolidated by SPS (Diameter size $=2.0 \pm 1.5 \mathrm{~nm}$ ).

Fig. 9. 3D ion maps of 14Hf mechanically alloyed powder (Video 1)

Fig. 10. 3D ion maps from 3 different regions of the 14Hf alloy consolidated by SPS. Volume with a) no clusters (Video 2), b) volume with a low number density of clusters (Video 3) and c) volume with a high number density of clusters (Video 4 ).

Fig. 11. a) Cluster size (Guinier diameter) distribution for high and low cluster density regions (cluster size $=2.34 \pm 0.77$ and $3.64 \pm 0.98$, respectively) and b) cluster shape for high and low cluster density regions in the $14 \mathrm{Hf}$ alloy consolidated by SPS. 
Fig. 12. O:Hf ratio as a function of the cluster size for for high and low cluster density regions in the 14Hf alloy consolidated by SPS.

Fig. 13. a) Nanoindentation hardness profiles for $14 \mathrm{Hf}$ as-milled powder and b) Vickers hardness measurements on 14Hf alloy consolidated by SPS. 


\section{Video captions}

Video 1. 3D view of the ion maps displayed in Fig. 9 for the 14Hf mechanically alloyed powder.

Video 2. 3D view of the ion maps displayed in Fig. 10-a) for the volume with no clusters in the 14Hf alloy consolidated by SPS.

Video 3. 3D view of the ion maps displayed in Fig. 10-b) for the volume with a low number density of clusters in the 14Hf alloy consolidated by SPS.

Video 4. 3D view of the ion maps displayed in Fig. 10-c) for the volume with a high number density of clusters in the $14 \mathrm{Hf}$ alloy consolidated by SPS. 


\section{Highlights}

- $\mathrm{Fe}-14 \mathrm{Cr}$ (wt.\%) and pure $\mathrm{Hf}$ powders were mechanically alloyed and consolidated by SPS

- Microstructural and mechanical characterisation has been performed

- The ability of $\mathrm{Hf}$ to produce a dispersion of oxide nanoparticles is demonstrated 
Table I. Chemical composition of the Fe-14Cr (wt. \%) pre-alloyed powder

\begin{tabular}{|l|l|l|l|l|l|l|l|}
\hline Element & $\mathrm{Fe}$ & $\mathrm{Cr}$ & $\mathrm{Si}$ & $\mathrm{Mn}$ & $\mathrm{C}$ & $\mathrm{N}$ & $\mathrm{O}$ \\
\hline Wt. \% & Bal. & 14.13 & 0.281 & 0.194 & 0.004 & 0.0095 & 0.052 \\
\hline
\end{tabular}


Table II. Summary of the cluster size, intercluster distance and number density of clusters in the 14Hf alloy consolidated by SPS in the low and high cluster density regions.

\begin{tabular}{|c|c|c|c|c|c|c|c|}
\hline \multirow{2}{*}{ Alloy } & \multicolumn{3}{|c|}{$\begin{array}{c}\text { Cluster size } \\
(\mathrm{nm})\end{array}$} & \multicolumn{3}{c|}{$\begin{array}{c}\text { Intercluster distance } \\
(\mathrm{nm})\end{array}$} & $\begin{array}{c}\text { Number density } \\
\text { of clusters } \\
\left(\times 10^{23} \mathrm{~m}^{-3}\right)\end{array}$ \\
\cline { 2 - 8 } & $\begin{array}{c}\text { Range } \\
(\mathrm{nm})\end{array}$ & $\begin{array}{c}\text { Median } \\
(\mathrm{nm})\end{array}$ & $\begin{array}{c}\text { Mean value } \\
(\mathrm{nm})\end{array}$ & $\begin{array}{c}\text { Range } \\
(\mathrm{nm})\end{array}$ & $\begin{array}{c}\text { Median } \\
(\mathrm{nm})\end{array}$ & $\begin{array}{c}\text { Mean value } \\
(\mathrm{nm})\end{array}$ & \\
\hline $\begin{array}{l}\text { Fe-14Cr-0.22Hf-SPS } \\
\text { (low cluster density) }\end{array}$ & $2.48-6.64$ & 3.67 & $3.64 \pm 0.98$ & $6.63-26.59$ & 16.86 & $17.81 \pm 6.84$ & 0.83 \\
\hline $\begin{array}{l}\text { Fe-14Cr-0.22Hf-SPS } \\
\text { (high cluster density) }\end{array}$ & $0.78-3.82$ & 2.26 & $2.34 \pm 0.77$ & $2.55-30.83$ & 13.39 & $14.43 \pm 7.81$ & 2.37 \\
\hline
\end{tabular}


Table III. Summary of the cluster shape in the regions with low and high number density of clusters in the14Hf alloy consolidated by SPS

\begin{tabular}{|l|c|c|c|c|}
\hline \multirow{2}{*}{ Alloy } & \multicolumn{4}{|c|}{ Cluster shape } \\
\cline { 2 - 5 } & Spherical & Disc shaped & Rod shaped & Lath shaped \\
\hline $\begin{array}{l}\text { Fe-14Cr-0.22Hf-SPS } \\
\text { (low cluster density) }\end{array}$ & $87 \%$ & $0 \%$ & $13 \%$ & $0 \%$ \\
\hline $\begin{array}{l}\text { Fe-14Cr-0.22Hf-SPS } \\
\text { (high cluster density) }\end{array}$ & $84 \%$ & $12 \%$ & $4 \%$ & $0 \%$ \\
\hline
\end{tabular}


Table IV. Summary of hardness, total hardening, Orowan and Hall-Petch contributions to the total hardening for the $14 \mathrm{Hf}$ alloy consolidated by SPS and $\mathrm{Fe}-14 \mathrm{Cr}-0.3 \mathrm{Y}_{2} \mathrm{O}_{3}$ (wt.\%) alloy consolidated by HIP [27, 45]. Hardness of Fe-14Cr consolidated by SPS is shown as the reference value [27].

\begin{tabular}{|c|c|c|c|c|c|c|}
\hline \multirow{2}{*}{ Alloy } & \multirow{2}{*}{$\begin{array}{l}\text { Hardness } \\
\quad(\mathrm{GPa})\end{array}$} & \multirow{2}{*}{$\begin{array}{c}\text { Total hardening } \\
\text { (GPa) }\end{array}$} & \multicolumn{2}{|c|}{ Orowan hardening } & \multicolumn{2}{|c|}{ Hall-Petch hardening } \\
\hline & & & $(\mathrm{GPa})$ & $(\%)$ & $(\mathrm{GPa})$ & $(\%)$ \\
\hline $\mathrm{Fe}-14 \mathrm{Cr}-\mathrm{SPS}$ [27] & $1.74 \pm 0.04$ & $-\ldots$ & - - - & $-\ldots$ & - - - & $-\ldots$ \\
\hline $\begin{array}{l}\mathrm{Fe}-14 \mathrm{Cr}-0.3 \mathrm{Y}_{2} \mathrm{O}_{3}-\mathrm{HIP} \\
{[27,45]}\end{array}$ & $3.60 \pm 0.08$ & 1.86 & 1.11 & 59.5 & 0.75 & 40.5 \\
\hline $\begin{array}{l}\mathrm{Fe}-14 \mathrm{Cr}-0.22 \mathrm{Hf}-\mathrm{SPS} \\
\text { (this study) }\end{array}$ & $2.31 \pm 0.13$ & 0.57 & 0.32 & 56.1 & 0.25 & 43.9 \\
\hline
\end{tabular}


Table V. Orowan hardness calculations for the 14Hf alloy consolidated by SPS considering the different cluster density regions observed by APT.

\begin{tabular}{|l|c|c|c|}
\hline Fe-14Cr-0.22Hf-SPS & $\begin{array}{c}\text { Partial Orowan hardening } \\
(\mathrm{GPa})\end{array}$ & $\begin{array}{c}\text { Volume fraction } \\
(\%)\end{array}$ & $\begin{array}{c}\text { Contribution to total } \\
\text { Orowan hardening } \\
(\mathrm{GPa})\end{array}$ \\
\hline High cluster density region & 0.329 & 35 & 0.115 \\
\hline Low cluster density region & 0.749 & 27 & 0.202 \\
\hline No clusters region & 0.000 & 38 & 0.000 \\
\hline
\end{tabular}




\section{Figure 1}

Click here to download high resolution image
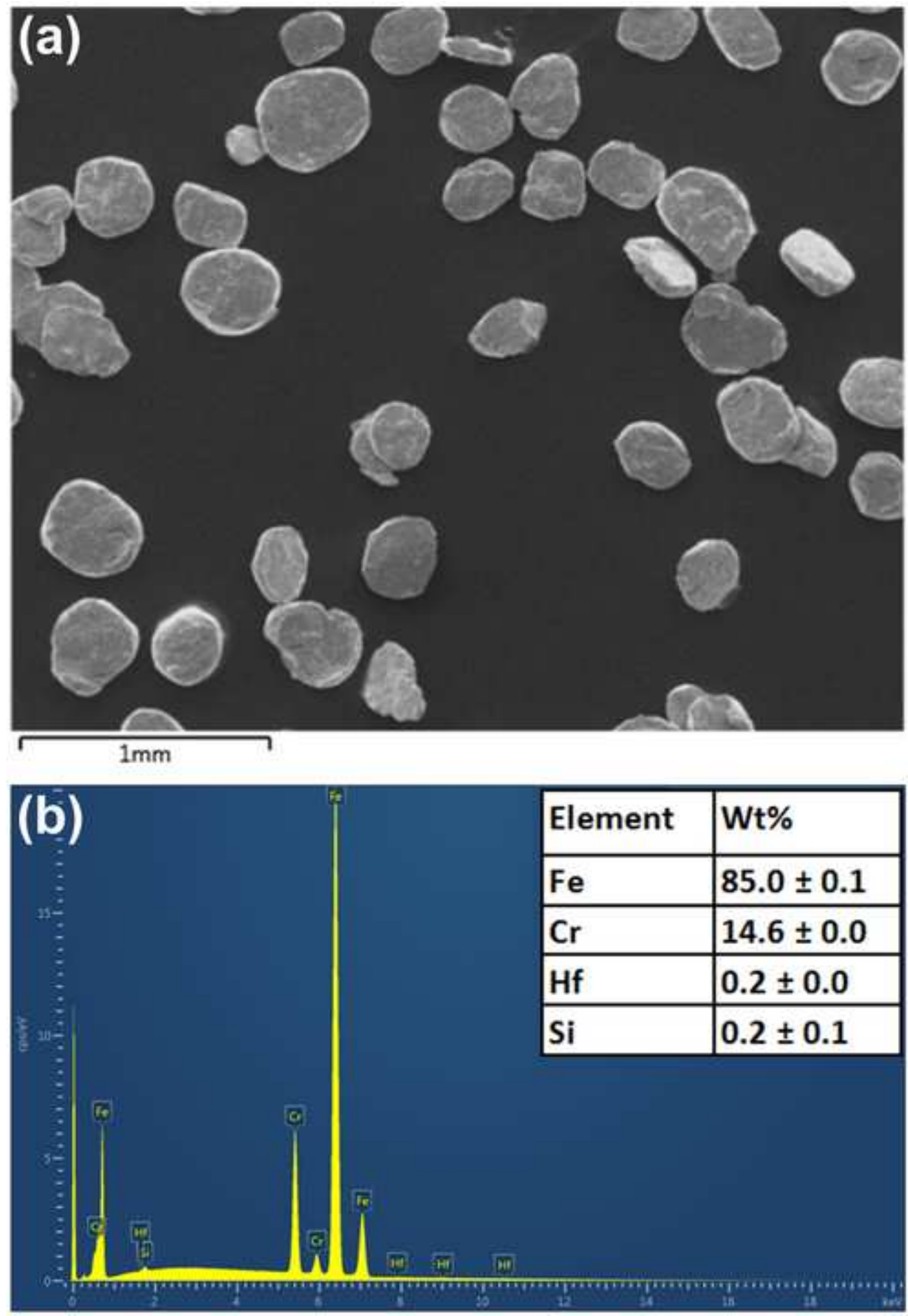


\section{Figure 2}

Click here to download high resolution image

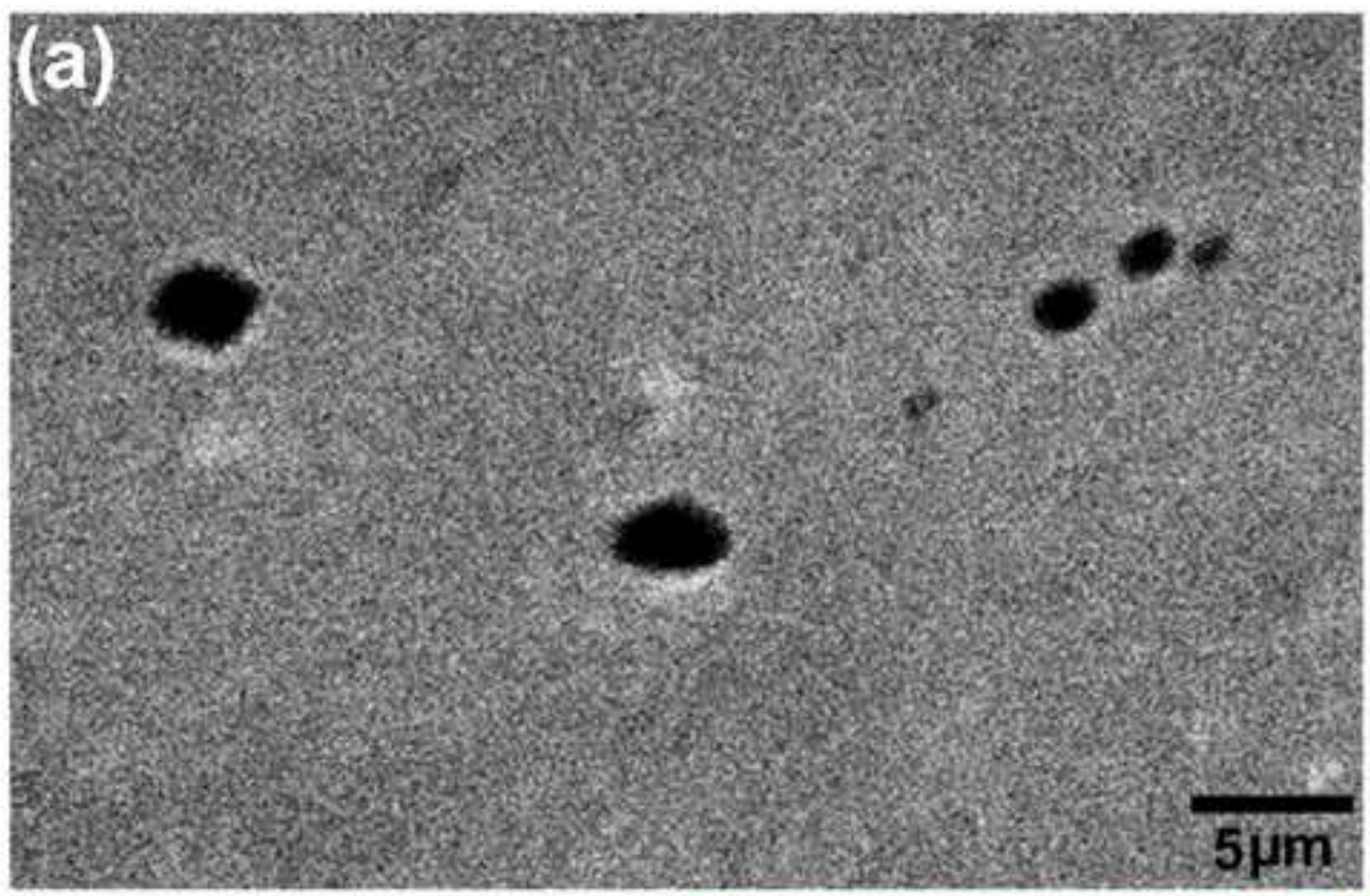

(b)

Fe K $\alpha 1$

$1 \mu \mathrm{m}$

$\mathrm{Cr} \mathrm{K} \alpha \mathrm{l}$ 

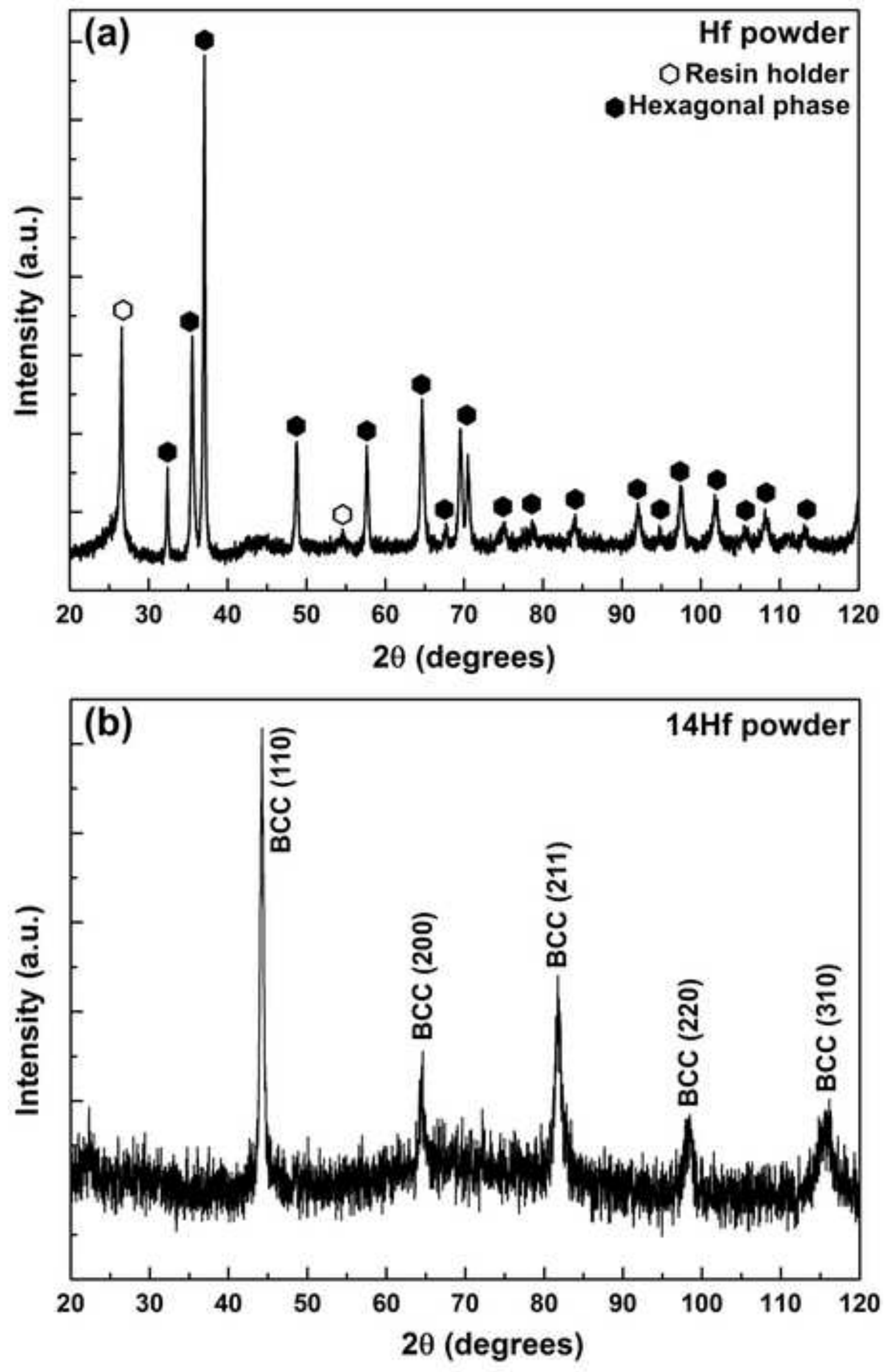


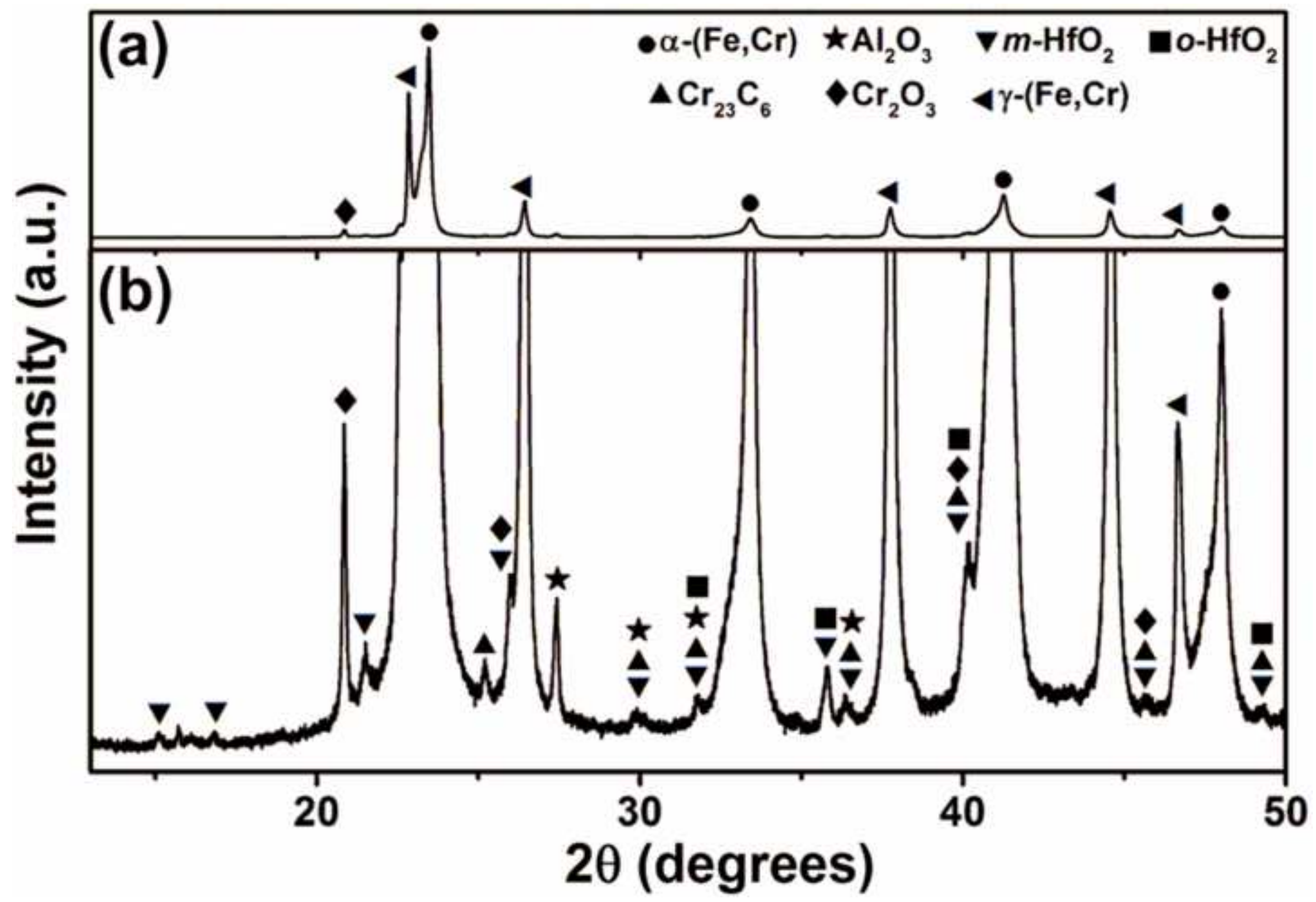



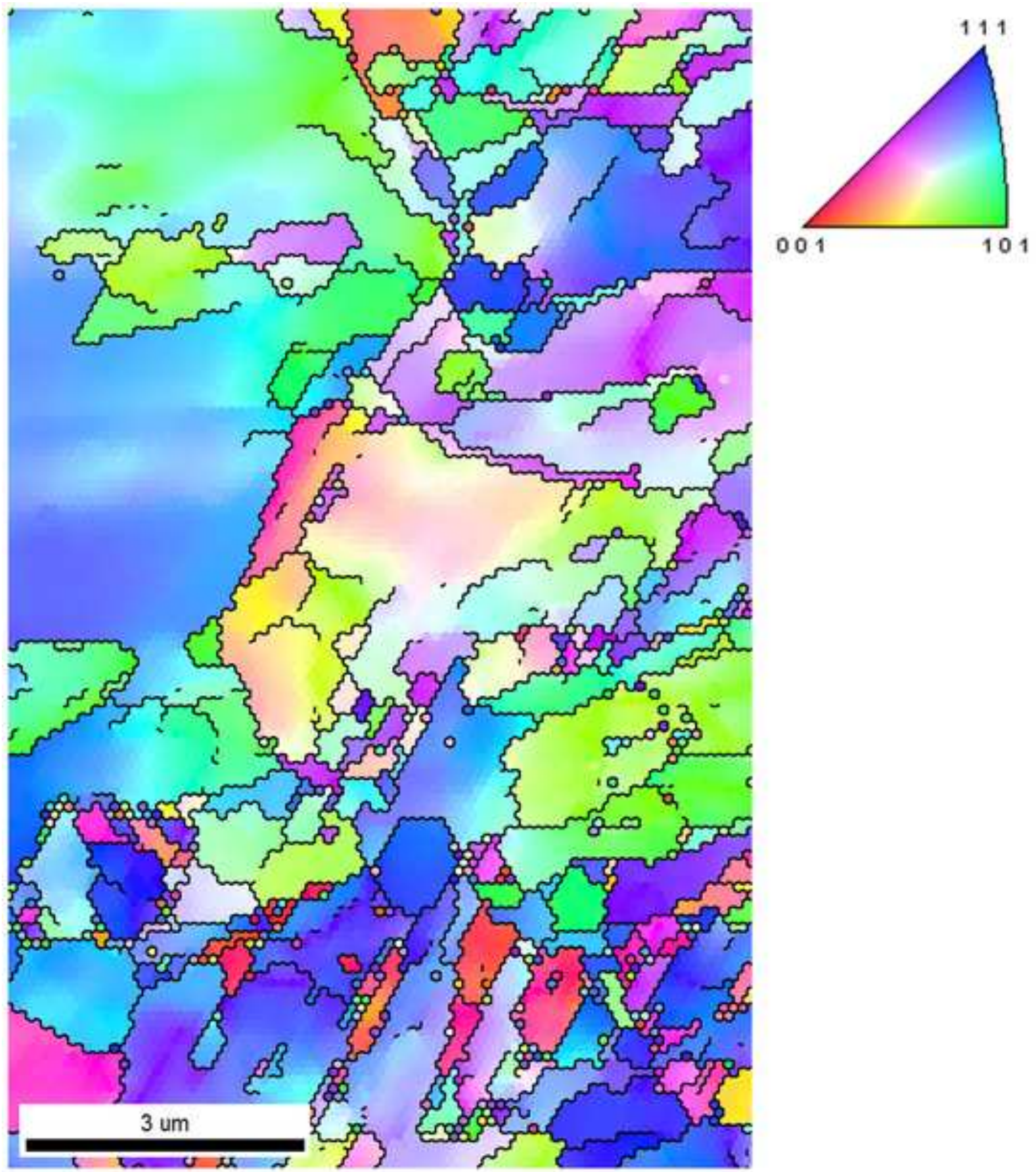


\section{Figure 6}

Click here to download high resolution image

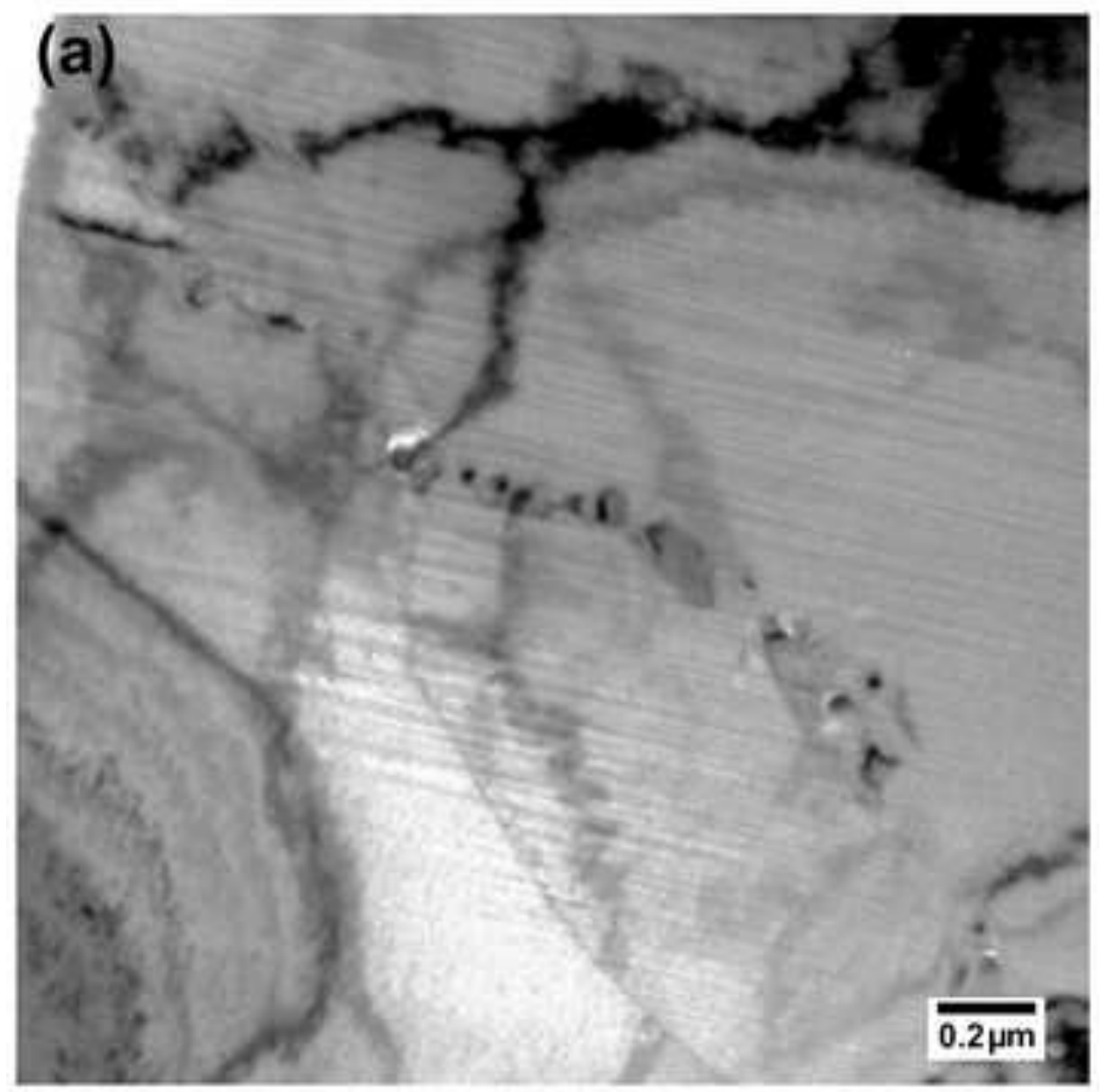

(b) 
Figure 7
Click here to download high resolution image
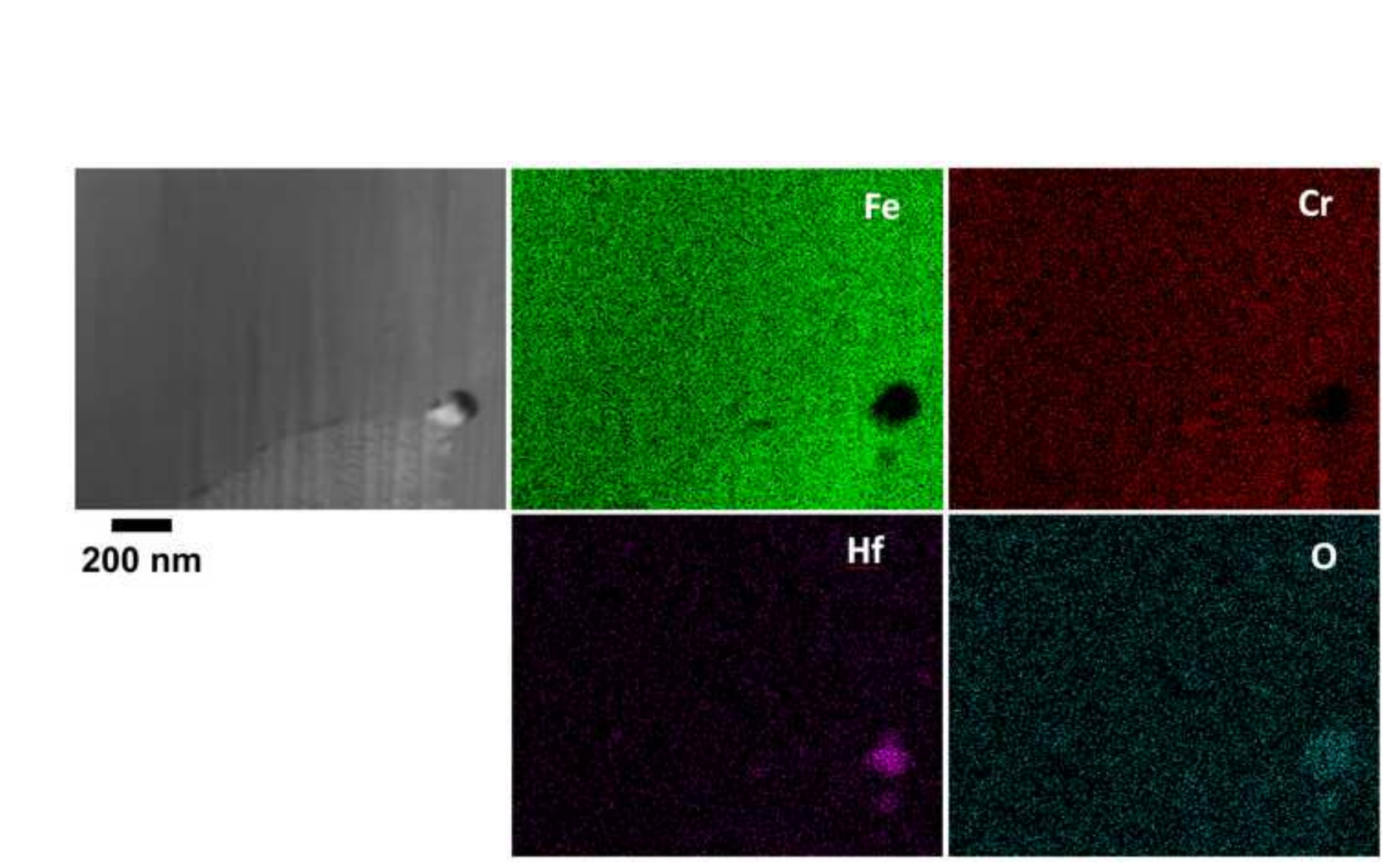

\section{$200 \mathrm{~nm}$}




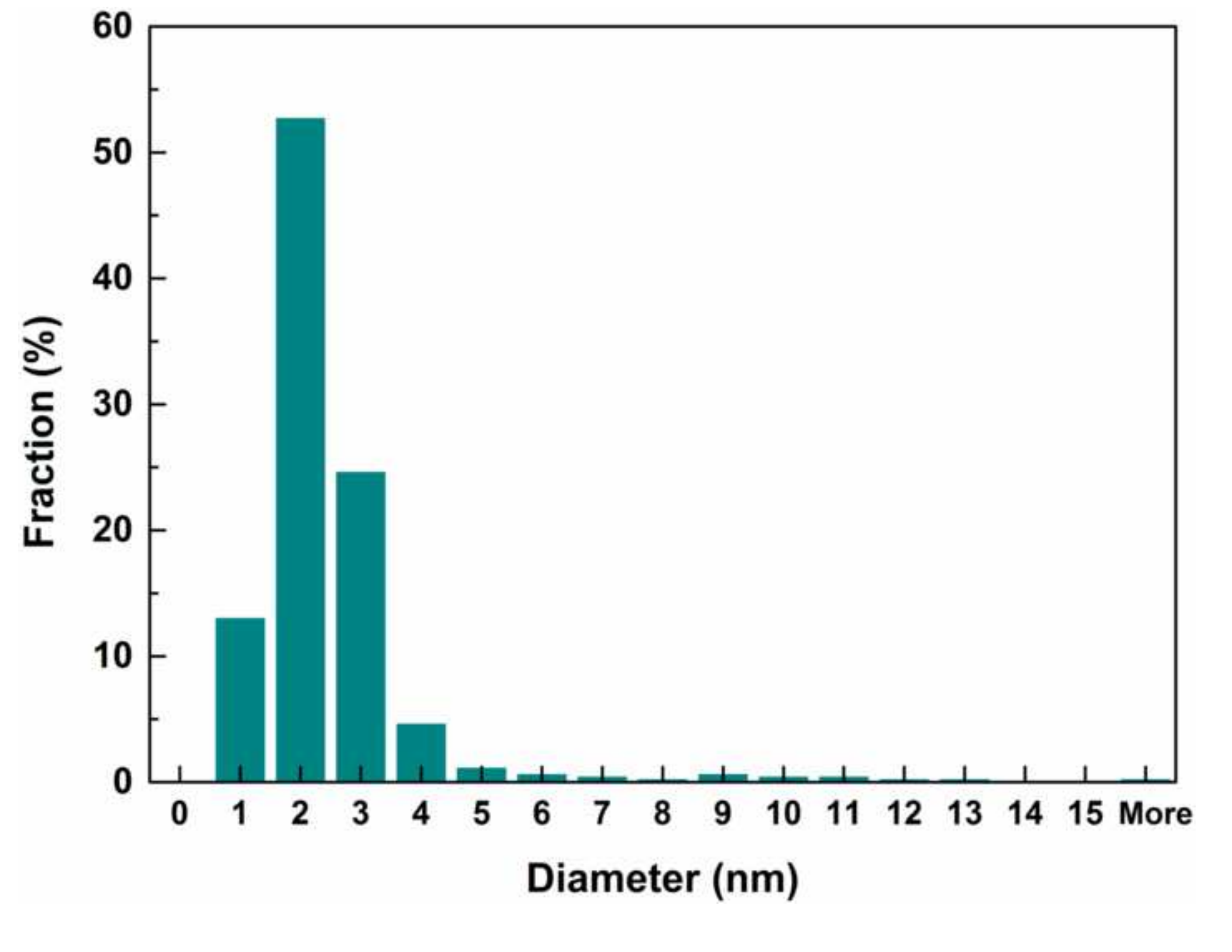

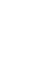


Figure 9

Click here to download high resolution image
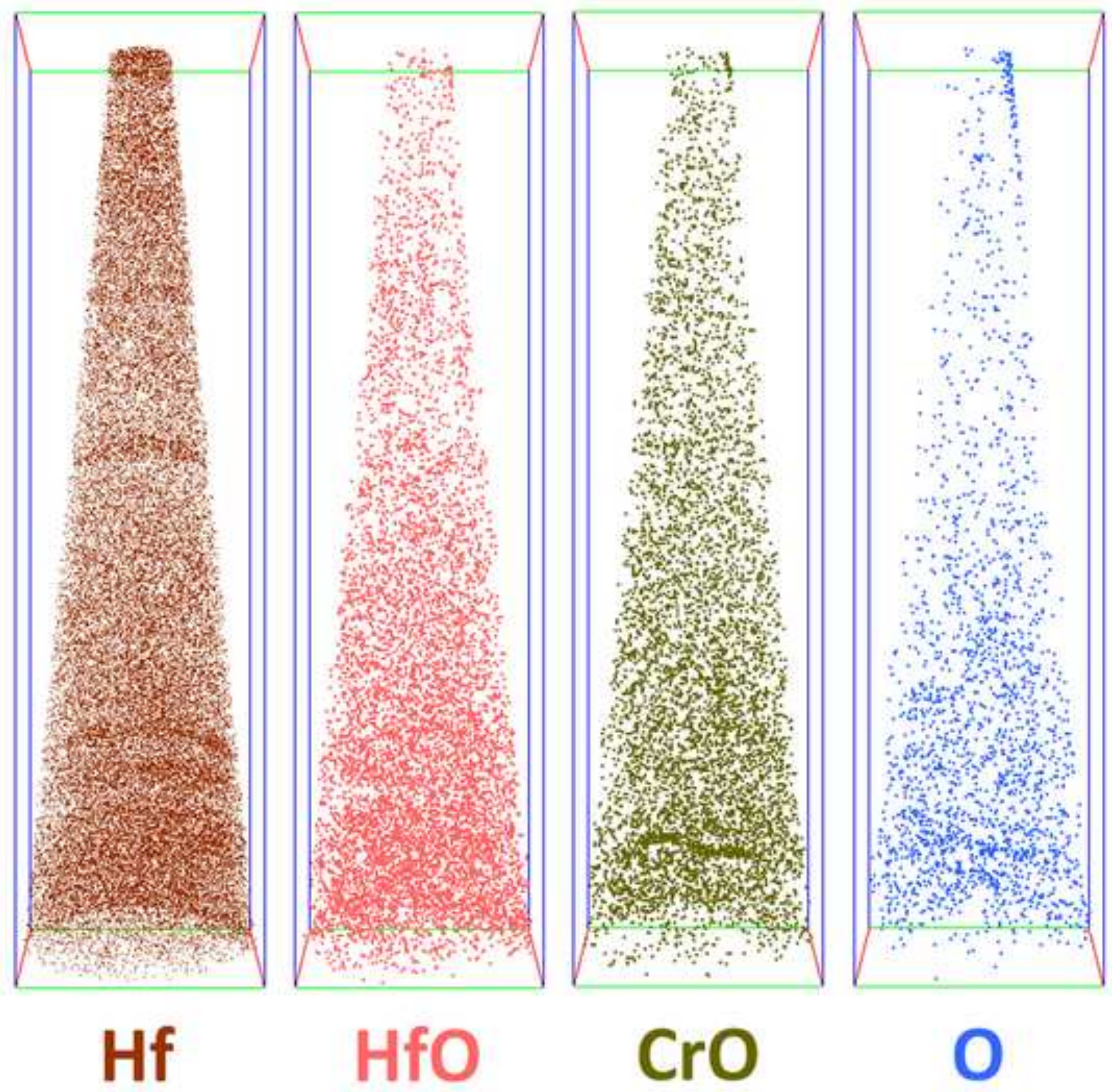

\section{$50 \mathrm{~nm}$}




\section{Fure 10}

Click here to download high resolution image
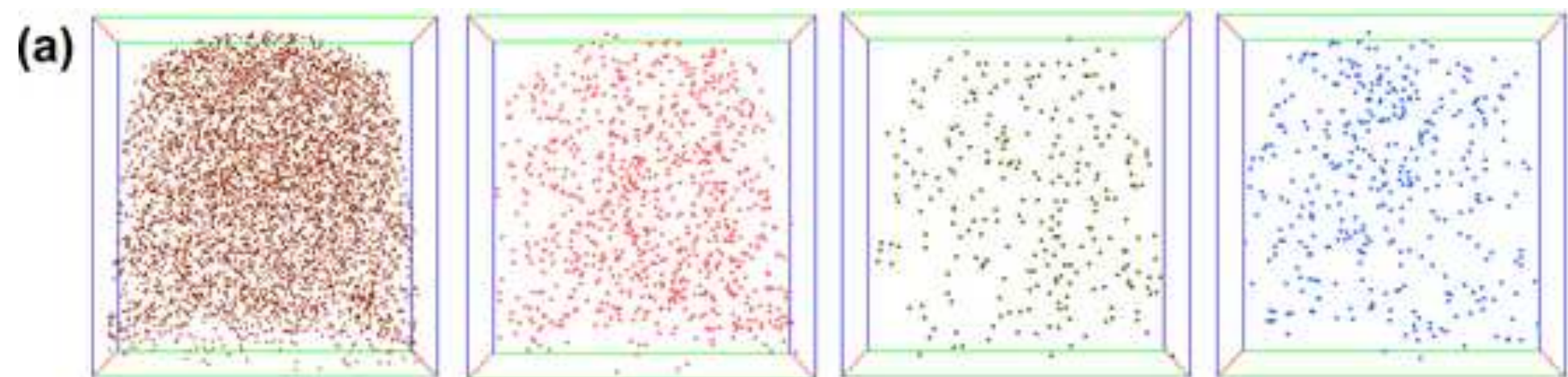

(b)
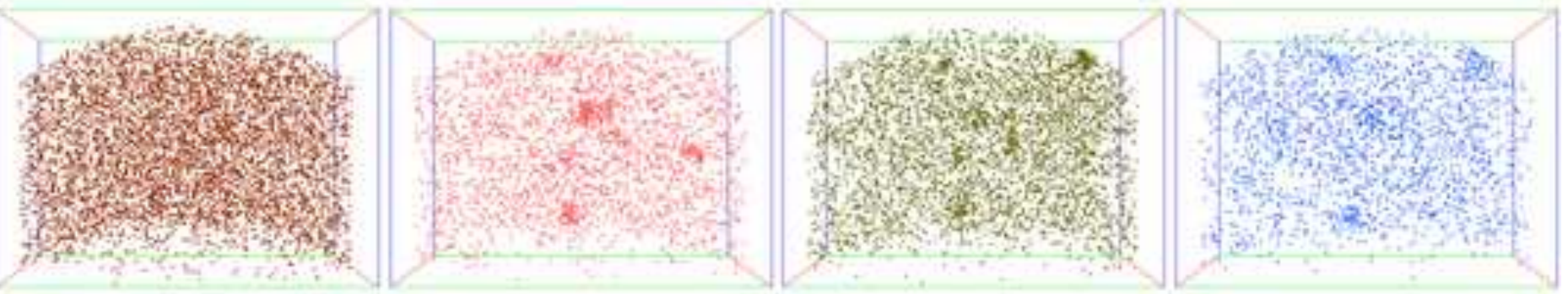

(c)
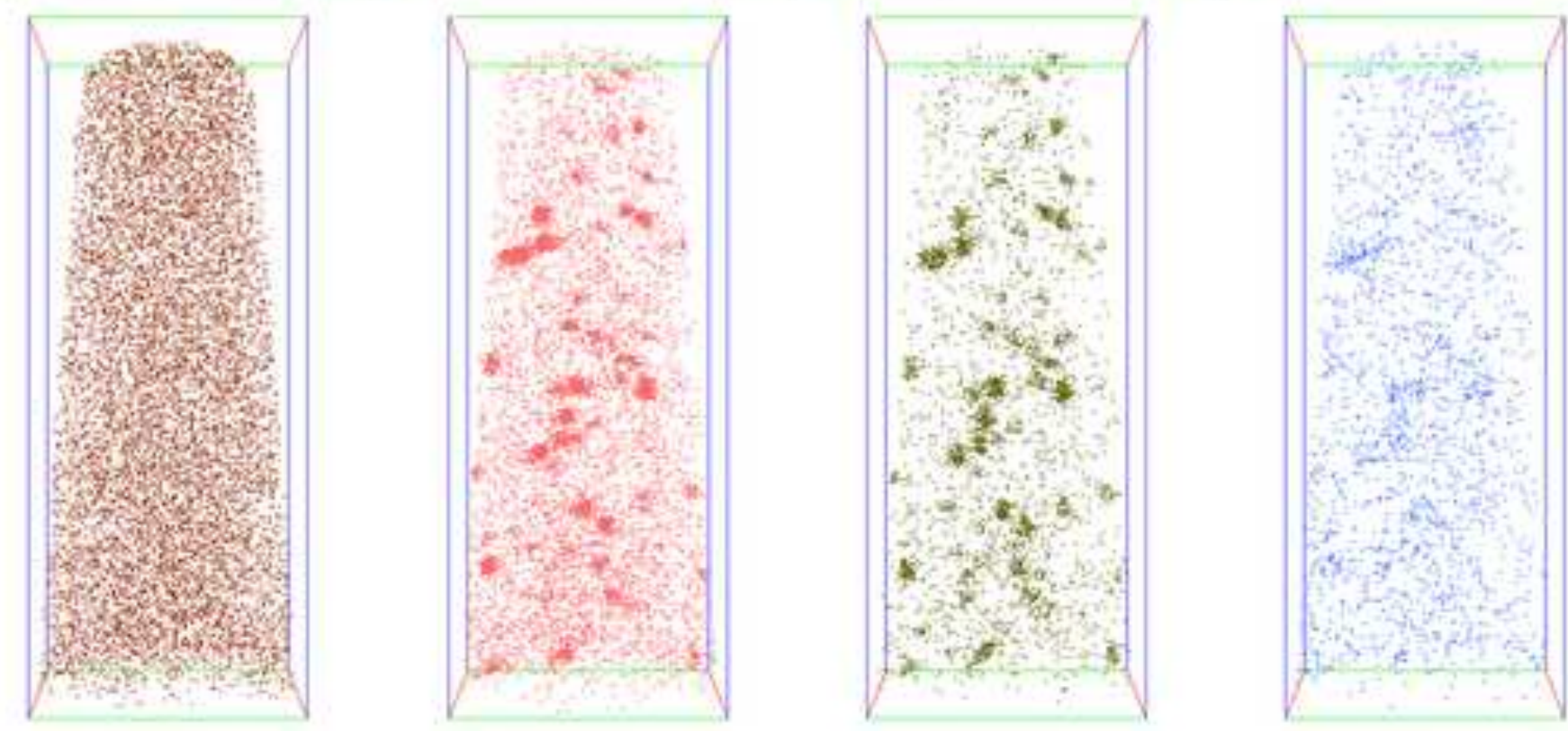

Hf

HfO

\section{$\mathrm{CrO}$}

o 
Click here to download high resolution image
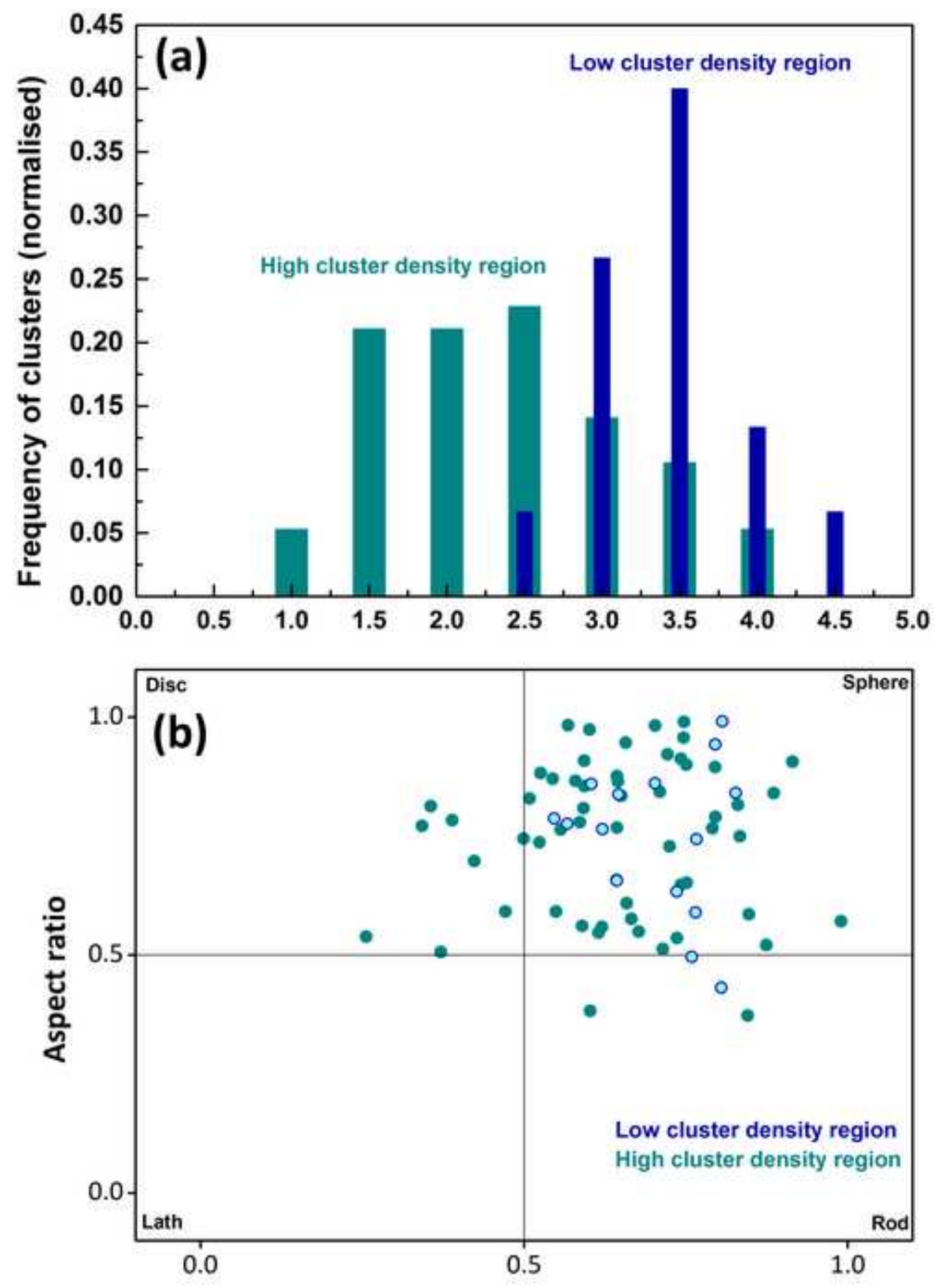

Oblateness 
Click here to download high resolution image

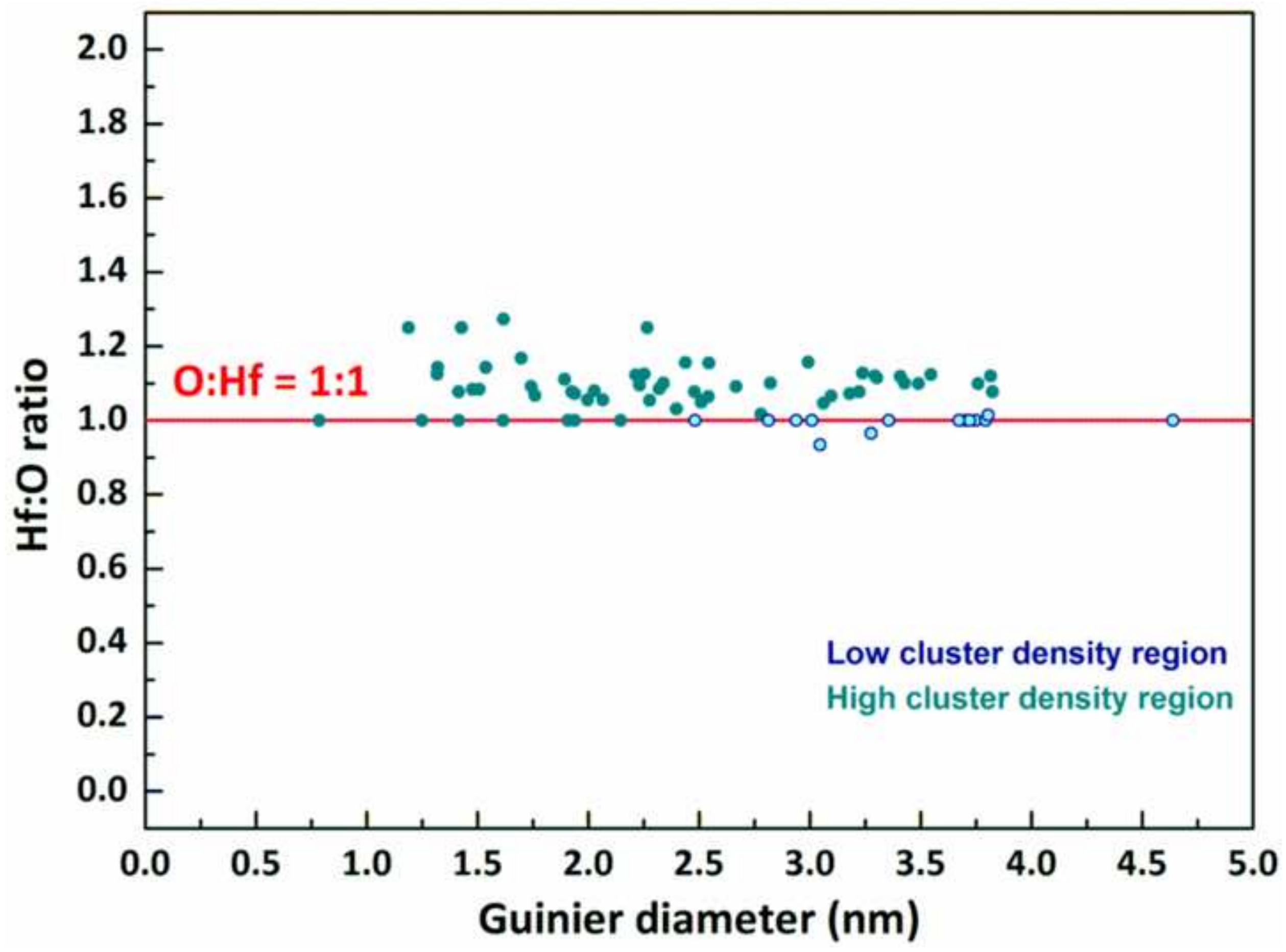


Click here to download high resolution image
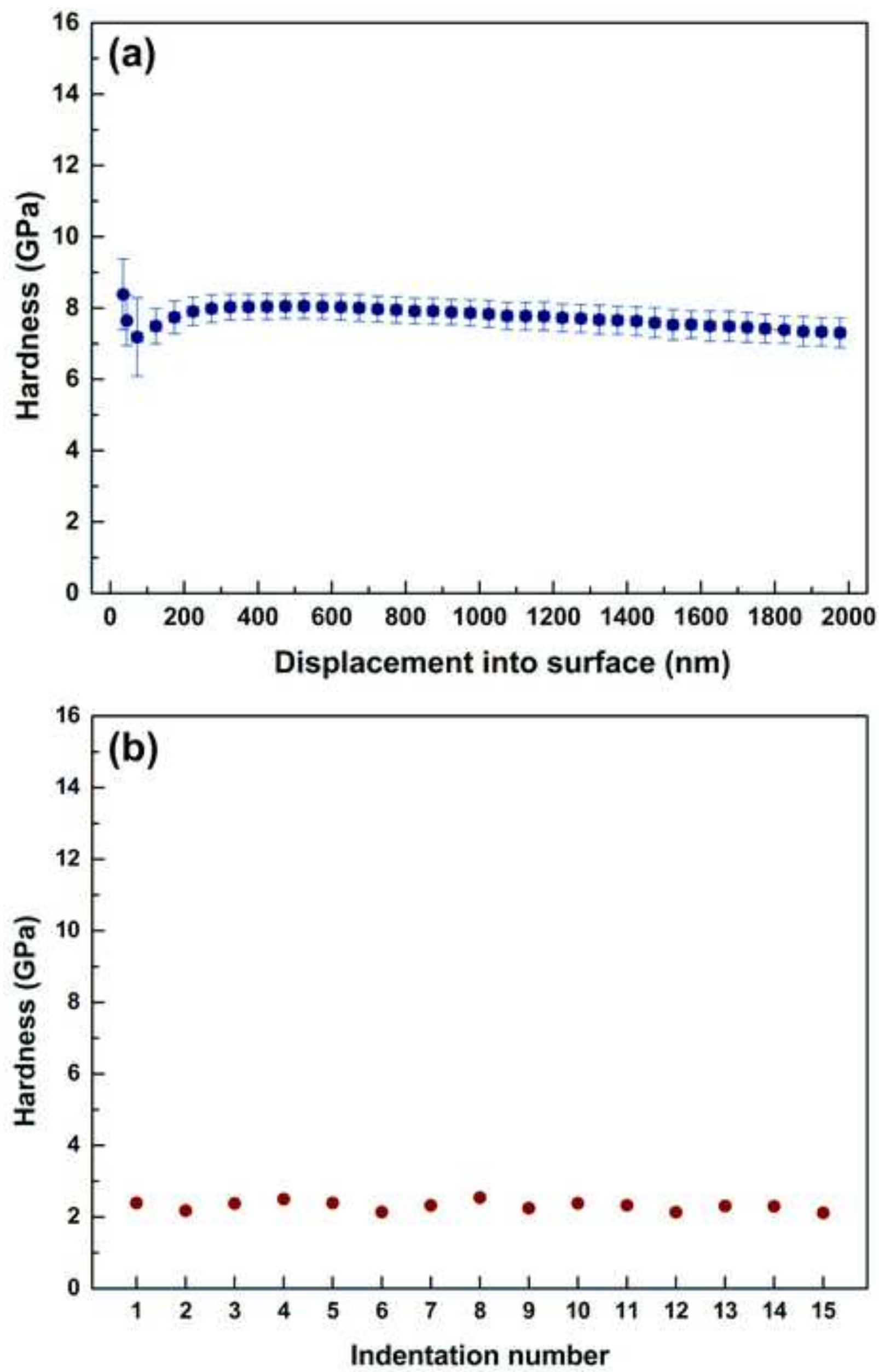
Video 1
Click he

Click here to download Supplementary Material for on-line publication only: JALCOM_APT-Fig_9.mp4

4

4

$\sqrt{2}+2$
$\sqrt{2}+x^{2}$

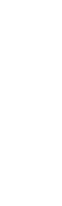
.

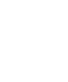
.

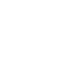
.

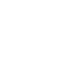
.

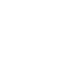
. (1) 
Video 2
Click he

Click here to download Supplementary Material for on-line publication only: JALCOM_APT-Fig10a.mp4

4

4
(1)

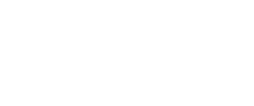

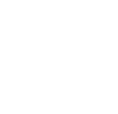

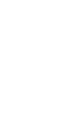
-

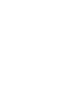

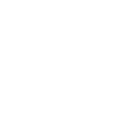

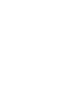
(1) (1) (1) (2) 
Video 3
Click he

Click here to download Supplementary Material for on-line publication only: JALCOM_APT-Fig10b.mp4 (

(2)

(1)

Cons

(1)

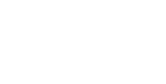

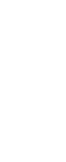
更 更 更 更 更 更 更 更 
Video 4
Click heı

Click here to download Supplementary Material for on-line publication only: JALCOM_APT-Fig10c.mp4

4

(1)

.

.

.

(1) 